\title{
EL COMERCIO DE LOS ESCLAVOS CANARIOS EN ITALIA A FINALES DEL SIGLO XV
}

\author{
Alberto Quartapelle* \\ cronicascanarias@gmail.com
}

\section{RESUMEN}

Desde su descubrimiento, las Islas Canarias han sido objeto del interés de mallorquines, castellanos y portugueses, quienes vieron en sus habitantes la oportunidad de hacerse de esclavos y de una ganancia fácil. Gracias a los datos recopilados por varios autores** y a nuevos documentos, el artículo reconstruye un cuadro sintético del comercio de estos esclavos en España y en Italia a finales del siglo xv. Particular atención se ha puesto en su origen, su destino, su composición por sexo y edad y en la estructura del precio de venta***. Palabras Clave: esclavos, Islas Canarias, siglo xv, Italia, Génova, Siena.

\section{THE CANARIAN SLAVE TRADE IN ITALY AT THE END OF THE 15TH CENTURY}

\section{Abstract}

From the moment of the discovery, the Canary Islands have been the object of interest to Majorcans, Castilians and Portuguese, who saw in their inhabitants the opportunity to obtain slaves and make an easy profit. Thanks to the data collected by various authors and to new documents, the article reconstructs a synthetic picture of the Canarian slave trade in Spain and in Italy at the end of the 15th century. Special attention has been paid in their origin, destination, sex and age composition and in the structure of the sale price. Keywords: slaves, Canary Islands, xv century, Italy, Genoa, Siena. 


\section{INTRODUCCIÓN}

Hasta el comienzo del siglo xx, el tema del comercio de los esclavos canarios no había despertado la atención de los historiadores. Solo en 1933, con la publicación de los documentos del Archivo General de Simancas que daban cuenta de la venta de los aborígenes gomeros en la baja Andalucía en 14891 a ser analizado y se evidencia que lo que durante siete siglos se llamó "conquista" fue, en muchas oportunidades, un saqueo sistemático de las riquezas de las islas ${ }^{2}$.

La esclavización de los aborígenes, que es parte de la historia del Archipiélago desde de su descubrimiento, llega a su máxima expresión en el último cuarto del siglo Xv, cuando el interés de los conquistadores se dirige a las islas mayores, La Gomera, Gran canaria y Tenerife. Como puede verse en las figs. 1 y 2, de los más de 1000 esclavos canarios capturados por los "conquistadores» y trasladados a Sevilla, Mallorca, Valencia, Barcelona u otras ciudades de la Península entre 1475 y 1500, casi el $90 \%$ se reporta en solo 7 ańos. En particular, cuatro son los episodios de esclavización de mayor relevancia por el número de esclavos y por la brutalidad:

1477: Hernán Peraza, hijo de Diego de Herrera, señor de La Gomera, con la colaboración de los tripulantes de dos carabelas de Palos y Moguer consigue capturar a 98 gomeros, tanto hombres como mujeres, y los vende como esclavos en Andalucía. Gracias a la intervención del obispo del Rubicón, fray Juan de Frías, los Reyes Católicos ordenan la liberación de todos los prisioneros: «Somos ynformados que algunas personas han traído ... algunos canarios de las yslas de Canarias que son cristianos e otros que están en camino para se convertir a nuestra Santa Fe católica ... e los venden por esclavos ...». "Lo qual es en grand deserviçio de Dios e nuestro (y) en detrimientos de nuestra Santa Fe católica ... los dichos canarios cristianos nin los questán en camino pueden ser cabtybos» ${ }^{3}$.

1489: en 1488 los gomeros, hartos de la violencia y las tropelías, matan al señor de la isla, Hernán Peraza, y sitian a sus hijos y a su esposa, Beatriz de Bobadilla, en la torre de San Sebastián. El Gobernador de Gran Canaria, Pedro de Vera, llamado para socorrer a doña Beatriz, después de una cruel represión

* https://independent.academia.edu/AQuartapelle.

** Serra RÀrols, E.: «De esclavos canarios», Revista de Historia Tomo 4, año 7, n. ${ }^{\circ} 25$, pp. 3-10». WöLfel, D.J: «Un episodio de la conquista de la Gomera» El Museo Canario 1933, pp. 5-84. Cortes, V.: "La conquista de las Islas Canarias a través de la venta de esclavos en Valencia», Anuario de Estudios Atlánticos n. 1 (1956). Franco Silva, A.: "La esclavitud en Andalucía al término de la Edad Media», Cuadernos de Investigación Medieval 1985. Gioffre, D.: «La schiavitù a Genova».

*** Un sincero agradecimiento a la paleógrafa Giustina Olgiati, del Archivio Nazionale di Genova, por su apoyo también en los tiempos de la pandemia de Covid 19.

1 Wölfel, D.J: $o p$. cit.

2 Marrero Rodríguez, M.: «La esclavitud en Tenerife a raíz de la conquista» Instituto de Estudios Canarios, 1966, p. 54.

${ }^{3}$ Rumeu de Armas, A.: «La política indigenista de Isabel la Católica» Instituto Isabel la Católica de Historia Eclesiástica - Valladolid 1969, p. 48-49 


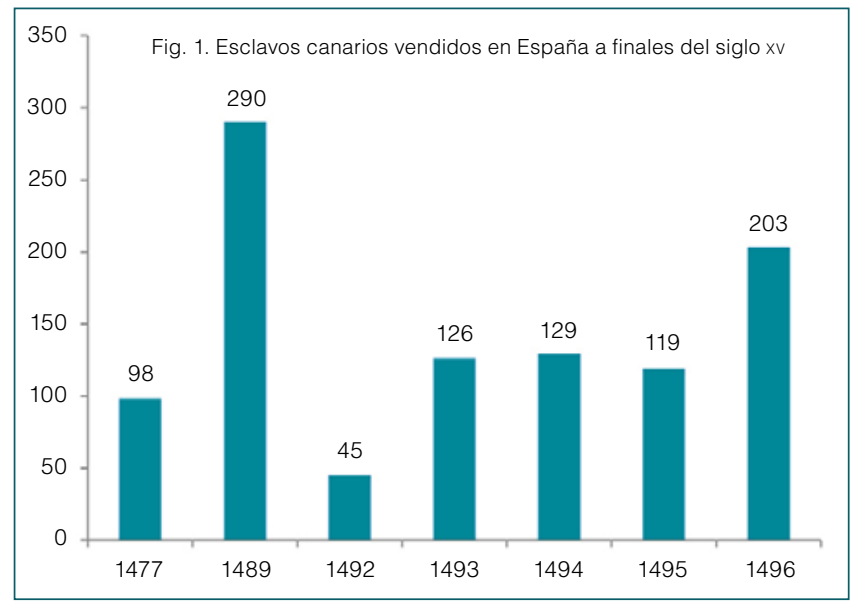

FIG. 2. ESCLAVOS CANARIOS VENDIDOS EN LAS PRINCIPALES CIUDADES DE LA PENÍNSULA (1475-1500)

\begin{tabular}{l|c|c|c|c|c|c|c|c|c|c|c|c|c|c|c|c|c|c}
\hline & TотаL & $75 / 6$ & 1477 & $78 / 83$ & 1484 & $85 / 8$ & 1489 & 1490 & 1491 & 1492 & 1493 & 1494 & 1495 & 1496 & 1497 & 1498 & 1499 & 1500 \\
\hline Sevilla & 67 & & & & 1 & & 1 & & & 2 & 1 & 1 & 7 & 40 & 3 & 1 & & 10 \\
\hline Valencia & 631 & & & & & & 39 & 2 & 13 & 29 & 125 & 126 & 110 & 158 & 26 & & 2 & 1 \\
\hline Mallorca & 90 & & & & & & 90 & & & & & & & & & & & \\
\hline Barcelona & 19 & & & & & & & 1 & & & & 2 & 2 & 5 & 4 & 3 & 2 & \\
\hline Palos & 272 & & & & & & 160 & & & 14 & & & & & & & & \\
\hline Total & 1079 & 0 & 98 & 0 & 1 & 0 & 290 & 3 & 13 & 45 & 126 & 129 & 119 & 203 & 33 & 4 & 4 & 11 \\
\hline
\end{tabular}

toma como botín de guerra a mujeres, mozos y niños y los envía a los puertos de la Baja Andalucía y de Mallorca para venderlos como esclavos. Gracias a la intervención del franciscano Miguel López de la Sierna, en 1490, los Reyes Católicos reconocieron que «las mujeres e niños e nińas non pudieron ser cabtivados ni vendidos» y ordenaron que «recogiesen ... los dichos canarios ... que fallaren en poder de qualsequier personas ... y los pusiesen en libertad». Desde Andalucía se rescataron y devolvieron a La Gomera 99 esclavos, mientras que nada se sabe de los 90 que fueron vendidos en Ibiza y de los 39 vendidos en Valencia. Solo sabemos que en 1500 seguían contándose 31 esclavos gomeros en Mallorca ${ }^{4}$.

4 Serra Ràfols, E.: op. cit., pp. 3-10. Wölfel, J.D.: «Los gomeros vendidos por Pedro de Vera y dońa Beatriz de Bobadilla", El Museo Canario, año i, n. ${ }^{\circ}$ I (1955) pp. 5-85. De la Torre, A.: «Los canarios de Gomera vendidos como esclavos en 1489». Anuario de Estudios Americanos, vol. 7 


\begin{tabular}{|c|c|c|c|c|c|c|c|c|c|c|c|c|c|c|}
\hline \multicolumn{15}{|c|}{ FIG. 3. ESCLAVOS CANARIOS POR SEXO Y EDAD (1475-1500) } \\
\hline & \multirow{2}{*}{ TотAL } & \multirow{2}{*}{ Palos } & \multirow{2}{*}{ Sevilla } & \multirow[b]{2}{*}{ MaLLORCA } & \multicolumn{9}{|c|}{ VALENCIA } & \multirow{2}{*}{ BARCELONA } \\
\hline & & & & & 1489 & $90 / 91$ & 1492 & 1493 & 1494 & 1495 & 1496 & 1497 & $98 / 00$ & \\
\hline Nińos & 202 & 41 & & & 14 & 14 & 20 & 9 & 30 & 40 & 2 & 21 & 3 & 8 \\
\hline Hembras & 302 & 14 & 34 & & 23 & 1 & 9 & 106 & 29 & 14 & 60 & 5 & & 7 \\
\hline Varones & 104 & 11 & 33 & & 2 & & & 10 & 2 & & 42 & & & 4 \\
\hline $\begin{array}{l}\text { No } \\
\text { especificado }\end{array}$ & 471 & 206 & & 90 & & & & 1 & 65 & 56 & 54 & 2 & & \\
\hline Total & 1079 & 272 & 67 & 90 & 39 & 15 & 29 & 125 & 126 & 110 & 158 & 26 & 3 & 19 \\
\hline
\end{tabular}

1492-1494: en junio de 1492 los reyes conceden a Alonso de Lugo, gobernador de Gran Canaria, el permiso para conquistar la isla de La Palma y de beneficiarse, como ayuda por los gastos, de los quintos de la corona de los captivos e ganados que tomara. En una ocasión, Lugo vende como esclavos a 25 rehenes que los bandos de la isla le habían entregado como prueba de paz y, sucesivamente, cautiva a otros 200 esclavos del bando de paz de Gazmira. Varios de estos palmeros fueron vendidos en Valencia.

1494-1496: terminada la ocupación de Gran Canaria, el Adelantado Alonso de Lugo dirige sus operaciones militares a la conquista de Tenerife en condiciones similares a las de La Palma. La guerra se prolonga más de lo esperado $y$, para financiar las operaciones y hacer frente a las deudas contraídas con algunos prestamistas italianos, decide apresar y vender como esclavos tanto a los isleños «de buena guerra» como a los de los bandos de paz.

Las investigaciones nos han consignado el sexo y la edad solo de la mitad de estos individuos. La fig. 3 muestra la distribución de mujeres, varones, niñas y niños menores de 15 años en las cinco ciudades de las cuales tenemos una suficiente cantidad de datos 5 .

Como puede apreciarse, la composición presenta en los años diferencias marcadas. Por ejemplo, en Valencia, en 1495 y 1497, se ofrecen en su mayoría nińos sin madre, mientras que en 1493 y 1496 llegan casi exclusivamente madres sin hijos ${ }^{6}$. Lo que hace pensar que los esclavistas ajustaban la oferta a la demanda para maxi-

(1950) pp. 47-72. Sevillano Colom, F.: «Los viajes medievales desde Mallorca a Canarias», Anuario de Estudios Atlánticos (1972) p. 42.

5 Se ha registrado la presencia de algunos esclavos canarios también en Jerez (13), Málaga y otras ciudades de la península.

${ }^{6}$ En Valencia un aspecto peculiar es la edad de los niños que se colocaba en el $80 \%$ de los casos entre los 8 y los 12 años, o sea en una edad demasiado temprana para su empleo como mano de obra en el campo o en la casa. 


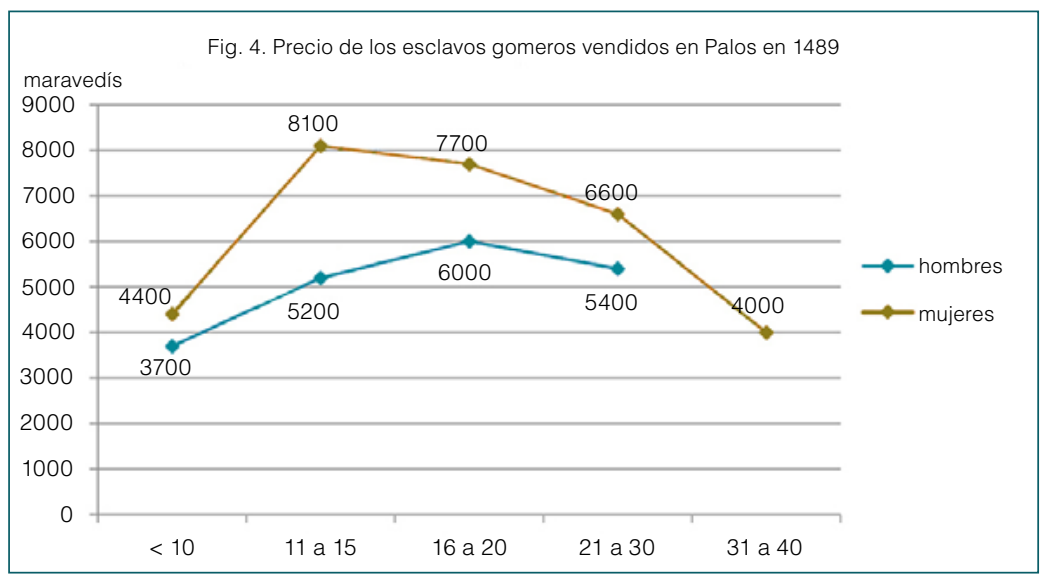

mizar el provecho. Es este el caso, por ejemplo, de Benito de Benavides, mercader de Puerto Santamaría, quien actuaba por cuenta del gobernador Alonso de Lugo, que el 28 de junio de 1494 había presentado a la Bailía General de Valencia 42 esclavos canarios entre los 6 y los 40 ańos. Seis meses después, el 9 de enero de 1495, el mismo Benavides pedía el permiso para reexportar parte de estos esclavos fuera del reino de Valencia, pues admitía que «no había sido capaz de venderlos a un precio aceptable» ${ }^{7}$ sin duda, por exceso de oferta, al considerar que en 1495 y 1496 habían llegado a Valencia 236 esclavos canarios.

Entre los parámetros que influían mayormente en el valor de los esclavos estaba el sexo y la edad. Como puede apreciarse en la figura 4, en Palos en 1489 las mujeres se vendían más caras que los hombres, y el precio bajaba a partir de los 20 años para los varones y de los 15 para las mujeres.

Algo similar se registraba en Barcelona: entre 1494 y 1498 las mujeres de 7 a 10 años se cotizaban a 38 libras barcelonesas, las de 11 a 15 años a 49 libras, las de 16 a 20 ańos a 50 libras y las mayores de 21 años a 34 libras. Los varones de 7 a 10 años se vendían por 27 libras barcelonesas y los mayores de 20 años a 32 libras.

En Valencia, al contrario, el valor de tasación de los esclavos no mostraba una diferencia entre los sexos.

La diferente valoración en función de la edad tenía una justificación económica: el esclavo/esclava se consideraba una inversión y su valor no podía no tener

${ }^{7}$ Benavides «demanda licencia de poder traure los dits catius fora de la present regne per mar com en aquelles no trobas preu competent, lo qual dit noble batle general era content puix asi era passat entre lo dit Benavides e lo dit magnifich lochtinent del batle general segons appar dessus en lo precedent acte donant licencia per poder les s'en portar li hon plaria», en Blumenthal, D.: Enemies and Familiars: Slavery and Mastery in Fifteenth-Century Valencia, Cornell University Press 2011 p. 52 nota 16. 


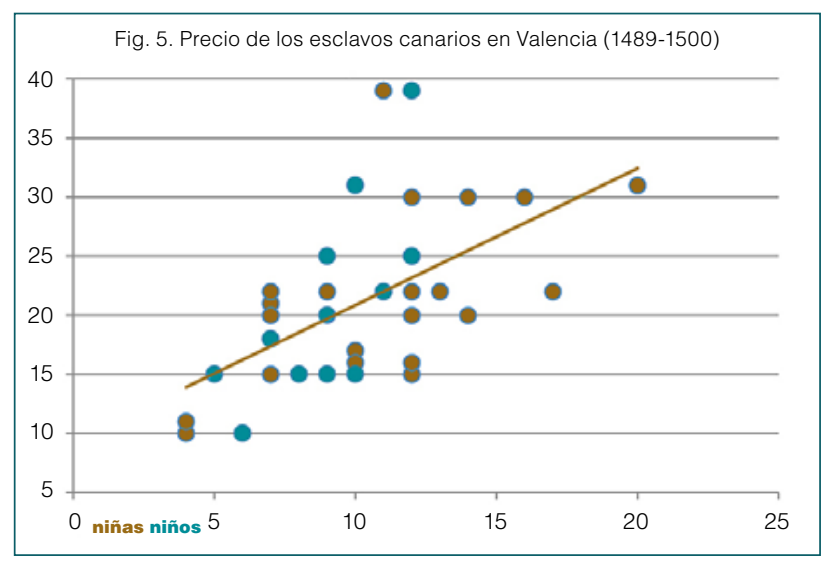

en cuenta su "vida residual», o sea, el tiempo durante el cual el dueño podía amortiguar el costo de la compra. Los esclavos más jóvenes se valoraban, por lo tanto, más que los esclavos más viejos.

En lo que concierne al sexo, los varones se cotizaban menos porque se dedicaban a actividades manuales de poco valor, como la agricultura y la industria, y llegaban a su máximo precio entre los 16 y los 20 años, que es cuando podían garantizarle al dueño fuerza física y resistencia al cansancio. Las mujeres se pagaban más porque eran empleadas en actividades domésticas de alto valor, como el cuidado de los nińos y de los ancianos y, por esta razón, en la mayoría de los mercados de la Península las más cotizadas eran las de 16 a 20 años. Sin embargo, en la baja Andalucía fueron las nińas de entre 11 a 15 ańos las que se vendieron al precio más alto. Una hipótesis es que estas niñas se consideraran más dóciles, más disponibles a modificar sus referencias culturales, más capaces de aprender las tareas domésticas y, por lo tanto, más fáciles de introducir en el ambiente familiar. Una segunda hipótesis toma en cuenta el aprovechamiento sexual de las esclavas por parte de los dueños. Por cierto, una menor de edad tenía mayor dificultad de oponerse a los «deseos» de su dueño. Lo que explicaría el increíble precio de 15000 maravedís pagado por un vecino de Sevilla por una muchacha de 14 años, valor difícil de justificar para la compra de una simple sirvienta.

\section{EL COMERCIO DE ESCLAVOS CANARIOS EN GÉNOVA Y EN ITALIA}

Si los comparamos con los más de 1000 canarios vendidos en la península ibérica, los 24 esclavos encontrados en Génova, Florencia, Siena, Venecia y Sicilia no parecerían añadir alguna información de interés (doc. 1). En realidad, la calidad de los documentos disponibles en los archivos italianos permite conocer aspectos 


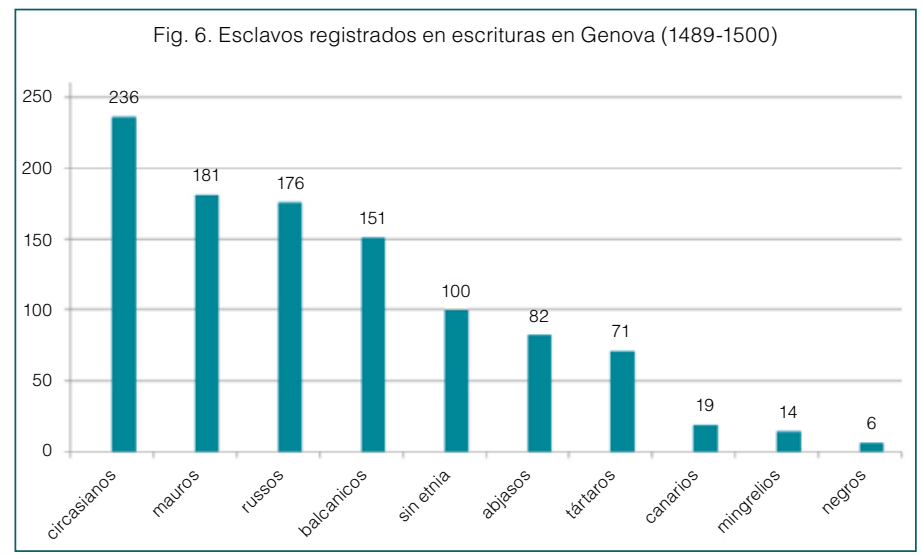

poco conocidos de la vida de estas personas reducidas injustamente a la esclavitud, porque se trataba de personas y no solamente de «esclavos».

Por cierto, la presencia de esclavos canarios en Italia no debe extrañar, pues en el siglo xv Génova, junto con Venecia, dominaba el comercio europeo de los esclavos orientales. Sus mercaderes gozaban también de una posición privilegiada en el archipiélago canario. Por ejemplo, eran genoveses Francisco de Riberol, Mateo Viña y Francisco Palomar, quienes en 1493 y 1495 financiaron la conquista de La Palma y Tenerife por parte del Adelantado Alonso de Lugo ${ }^{8}$. Era también genovés aquel «Johanot Otobo de Mor, mercader jenoves» (Giovanni Ottobono de Mari') que en agosto de 1494 transportó 65 esclavos tinerfeños desde La Gomera a Valencia por cuenta de Alfonso Sanchis, tesorero del rey ${ }^{10}$.

Sin embargo, a pesar de estas condiciones favorables que hubieran permitido a los genoveses participar como protagonistas en el comercio de esclavos canarios, estos representan solo el 1,4\% del total de los esclavos comercializados en la ciudad entre 1450 y 1500.

La composición por sexo y edad de los canarios encontrados en los escritos italianos no difiere mucho de la de las otras etnias, con una absoluta prevalencia de las mujeres con respecto a los varones (87\%), y una edad media de 22 años. El fenó-

${ }^{8}$ Por su participación a esta empresa el Duque de Medina Sidonia recibió 40 esclavos.

9 Erróneamente C. Verlinden reconoce en este personaje un posible miembro de la familia de aquel Usodimare que había acompañado el veneciano Alvise da Ca da Mosto en sus viajes de descubrimiento en África en 1455 por cuenta de Enrique el Navegador. Verlinden, C. «La esclavitud en Canarias» IV Coloquio de historia canario-americana, vol. 1, 1982, p. 23. En 1494 tenemos noticia de la presencia de este mercader en la colonia genovesa de Barcelona. Madurell, I. y Marimon, J-M.: "Ambrogio Fatinati, mercader genoves a Barcelona (1472-1497)» p. 528 en Atti del $1 .{ }^{\text {er }}$ Congresso Storico Liguria-Catalogna, 1969.

${ }^{10}$ Cortes, V.: op. cit. p. 35. 


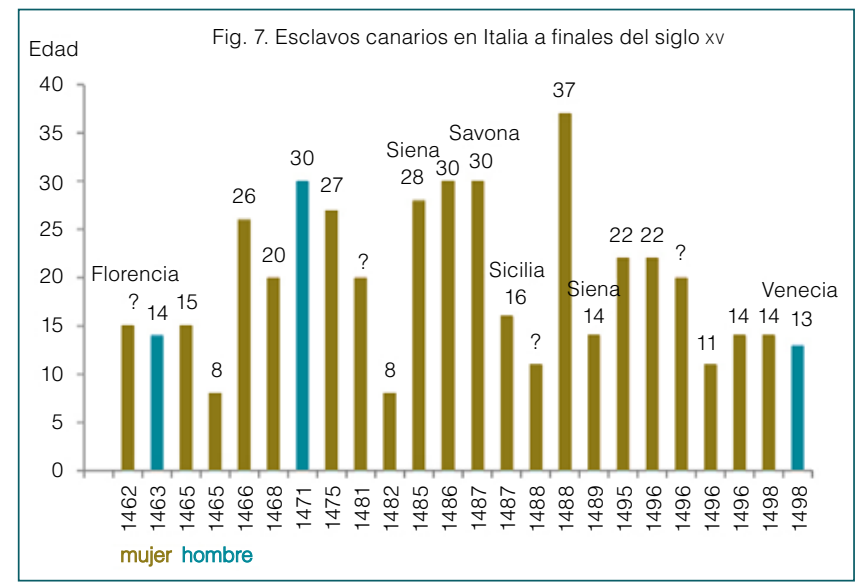

meno se explica por la utilización, en todo el centro y norte de Italia, de la mano de obra esclava casi exclusivamente en las labores domésticas.

Como puede verse en la fig. 7, se han encontrado esclavos canarios no solo en Génova, sino también en otras ciudades italianas. En realidad, todas las transacciones de estos esclavos, con excepción de un Martinico vendido en Venecia en 1498, están relacionadas con los mercaderes genoveses.

Probablemente, el primer esclavo canario aparecido en Italia fue el mauro Lanzaroto del que solo sabemos que se escapó de su dueño genovés en 1425 junto con otro esclavo de origen circasiano ${ }^{11}$. Su nombre y su edad hacen pensar que podría ser uno de los esclavos enviados para ser vendidos en Francia en 1410 por el gobernador de Lanzarote, Maciot de Bethencourt, con el fin de financiar la conquista de la isla.

Sin embargo, es solo a partir de la segunda mitad del siglo xv, cuando el mercader genovés Centurioni envía desde Sevilla a Florencia una muchacha de 15 años, que en los actos notariales italianos empiezan a aparecer procedencias de progenie maurorum canariorum, maura de canaria o de progenie maurorum seu canariorum.

En una primera fase, los genoveses actúan como simples intermediarios comerciales entre los reinos de Castilla y de Cataluña. Compran esclavos canarios en Sevilla y en la baja Andalucía y los venden en Génova a mercaderes de Mallorca, Valencia o Barcelona, como es el caso del joven Jacobino de progenie maurorum canarie de 30 años quien, como una mercadería cualquiera, llega a Génova el 20 de octubre de 1462 en un barco procedente de Sevilla, junto con 442 sacos de lana,

${ }_{11}$ El nombre Lanzaroto podría no tener relación con la Isla de Lanzarote en el Archipiélago canario. En 1410 en Génova se registra la venta de un esclavo ruso de 12 años de nombre Lanzarottos. 
16 pacas de cochinilla y una mula ${ }^{12}$. Tan solo dos meses después, el 22 de enero de 1463, Jacobino pasa de mano, comprado por 25 ducados por el mercader mallorquín Giovanni Focoberto ${ }^{13}$ (doc. 1).

En 1465 tuvo un destino similar la joven maura de Canaria Caterina de 20 años, adquirida por el mismo mercader genovés Centurioni en Sevilla, quien fue embarcada hacia Génova ${ }^{14}$ y vendida por 122 liras otra vez al mallorquín Focoberto con destino Mallorca.

En total, de los cinco esclavos canarios vendidos en Génova entre 1463 y 1468 , cuatro se reembarcan inmediatamente rumbo a Cataluña y Mallorca. Esta circunstancia no tiene que hacer pensar que existía un particular interés de los catalanes por los esclavos canarios. En realidad, durante el siglo XIV y la primera mitad del siglo xv, Génova era el principal mercado esclavista del Mediterráneo Occidental y cientos de rusos, tártaros, circasianos y otros esclavos orientales llegaban a Génova para ser redistribuidos en Italia, Francia y en la península ibérica. Solo entre 1450 y 1475 se registran en Génova más de 48 ventas de esclavos y esclavas a mercaderes españoles. Un ejemplo es Giovanni Focoberto quien compra él solamente, además de los dos canarios citados, dos esclavos circasianos, un abjasio, una esclava búlgara y otra rusa ${ }^{15}$.

Después de esta primera fase, los esclavos canarios dejan de ser una simple mercadería en tránsito hacia Espańa y pasan a formar parte de la sociedad del centro norte de Italia. En las actas notariales, los canarios ya no son solamente objeto de compra y venta, sino que son asegurados contra los riesgos del parto, como Cazina de 26 años, en 1466, o se alquilan como Janicho, de 30 años, rentado por 8 años en 1471; o se le reconoce el derecho a la libertad, como a Caterina de 37 años, manumisa en 1488 por Primaflore Ragio, o se dejan en donación a través de testamento, como otra Caterina donada por Barnaba Salvago a su esposa en 1496.

Desafortunadamente, poco sabemos de la procedencia de estos canarios. Los documentos confirman solo el origen de María, en 1481, procedente de La Gomera y adquirida en Sevilla por Antonio de Bargaglio. Algunos de ellos, como Cazina

12 El barco era del mercader vasco Juan Lopez d'Ondàrroa procedente de Sevilla, Barcelona, Tortosa y Pisa y transportaba 442 sacos de lana, 16 pacas de cochinilla, 3.300 piezas de cuero, 155 barriles de atún, 1 mula y el joven esclavo Jacobino. ASGe Bartolomeo Canessa, f. 1, a. 16, en Heeers, J. «Le commerce de Basques en Méditerranée au xv siecle (dapes les archives de Genes)», en Bulletin Hispanique, tome 57, n. ${ }^{\circ}$ 3, 1955, pp. 292-324. Por error Heers indica a p. 309 la fecha de 1472.

${ }_{13}$ ASGe Tommaso Duracino f. 7, a. 16. Giovanni Focoberto era probablemente el mercader Juan de Fontcuberta, de una familia de judíos conversos en el siglo Xiv. Pistarino, G.: «Tratta di schiavi da Genova in Toscana nel secolo XV», en Studi di economia toscana nel Medioevo e nel Rinascimento in memoria di Federigo Melis, Pisa (1987), pp. 285-304

${ }^{14}$ Hers, J.: Genes au XV siècle: activité economique et problèmes sociaux, SEVPEN, 1971 pp.

15 La compra de esclavos era una parte relevante de la actividad de los mercaderes catalanes que operaban en Génova. Los catalanes, no estando autorizados a tratar directamente con mercaderes extranjeros, tenían que utilizar forzosamente para sus compras intermediarios genoveses. Heers, J.: «Les catalans à Genes vers 1450», en Atti del III Convegno Internazionale di Studi Colombiani, Genova 1977, p .49. 
en 1466, Janicho en 1471 y Aranicha en 1482, venían probablemente directamente desde el Archipiélago como fruto de capturas corsarias y el nombre aborigen podría indicar que no habían sido bautizados antes de llegar a Génova.

Por último, se puede inferir que es la isla de Tenerife el origen de una de las dos esclavas vendidas en 1496, Margherita de 22 años, u otra sin nombre de 14, quienes llegan directamente (ad dricturam) desde Valencia ${ }^{16}$. Estas esclavas podrían ser parte de las 24 mujeres y los 18 varones llevados a Valencia por Benet Benavides en 1494, por cuenta de Alonso de Lugo. Como indica el registro de la Bailía de Valencia, el 9 de enero de 1495 «al no haber encontrado para ellos un precio adecuado», Benavides es autorizado a reexportar parte de estos esclavos "donde quiera ${ }^{17}$.

\section{EL VALOR DE LAS ESCLAVAS CANARIAS}

Los actos notariales de Génova nos permiten calcular el valor que se les daba a las esclavas canarias. Para este fin se han utilizado los once precios de venta registrados en el período que va desde 1465 a 1498. El precio mínimo fue de 68 liras genoveses para la maura de canaria Caterina de veinte años, vendida en 1468 por Pietro di Pietra al valenciano Gabriele Marco. El precio máximo fue de 200 liras por Anna de progenie maurorum canarie, de 14 años, cedida en 1498 por el magnificus dominus Francesco Cibo a Pietro de Mari.

El precio promedio era de 129 liras y puede considerarse una cantidad relevante para la época, ya que equivalía a 3 toneladas de trigo o a tres ańos de sueldo de un marinero ${ }^{18}$. Sin embargo, si lo comparamos con el valor de las esclavas de otras etnias puede notarse que las esclavas canarias estaban entre las menos cotizadas del mercado. Como puede verse en la fig. 8, entre 1460 y 1500 el precio pagado por las canarias es $40 \%$ más bajo que el precio de las esclavas orientales y solo un poco superior al de las esclavas negras.

Para verificar si la baja cotización de las esclavas canarias podía explicarse por las características propias del mercado esclavista genovés, se ha controlado el precio de todas las esclavas compradas en Génova por los mercaderes catalanes para su reexportación a Mallorca, Valencia y Barcelona entre 1460 y 1470 . Como puede verse en la fig. 9, también en este caso las esclavas orientales eran cotizadas entre un $50 \%$ y un $90 \%$ más caras que las canarias.

16 Giofrè̀, D.: «Il commercio d'importazione genovese alla luce del registro dei dazi 14951537», en Studi in onore di Amintore Fanfani, Gioffrè Editore (1962), vol. 5 p. 144.

179 de enero de 1495: Benavides «demana licencia de poder traure los dits catius fora de la present regne per mar con en aquelles no trobas preu competent lo qual dit noble batle general dix era content puix axi era passat entre lo dit Benavides e lo dit magnifich lochtinent del batle general segons appar dessus en lo precedent act donant licencia per poder les s'en portar li hon plaria» en BlUMENTHAL, D.: op. cit., p. 52. Hay que notar, todavía, que entre las esclavas presentadas por Benavides ninguna tenía menos de 20 años. Cortes v. op. cit., p. 54.

18 Gioffre, D.: «La schiavitù a Genova» op. cit., p. 142. 

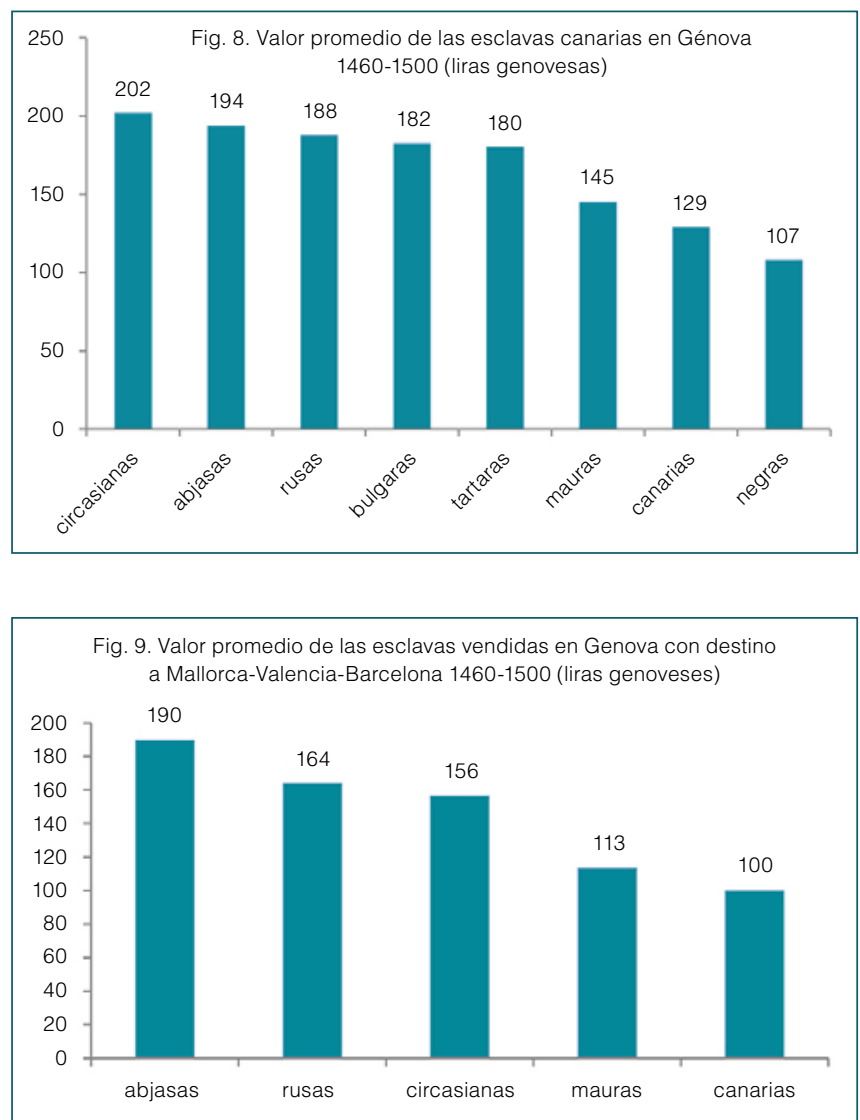

Esta baja cotización es confirmada también en los mercados de la península ibérica. En el período que va desde 1479 a 1516, las esclavas canarias entre los 14 y los 30 años se pagaban a 55 libras en Barcelona, casi el mismo precio que las mauras $^{19}$ del Magreb (54 libras) y las del Sultanado de Granada (52 libras). Las esclavas más baratas eran las procedentes de la alta Guinea, Senegambia y Barqah con precios de 40, 34 y 40 libras $^{20}$ respectivamente. Sin embargo, hay que considerar que en este período se registra una llegada masiva de esclavas africanas.

19 En Génova se indicaba con el término mauro tanto a los esclavos procedentes de España como a los bereberes del norte de África. Sin embargo, el número de esclavos mauros llega a ser significativo solo después de 1470, cuando empieza la guerra de Granada. Entre el 1475 y el 1499 la venta de esclavos «mauros» representa el 31,5\% del total. HeErs, J.: Esclaves et domestiques au moyen-age, Fayard (1981) p. 28.

20 Armenteros Martínez, I.: op. cit., p. 502. 


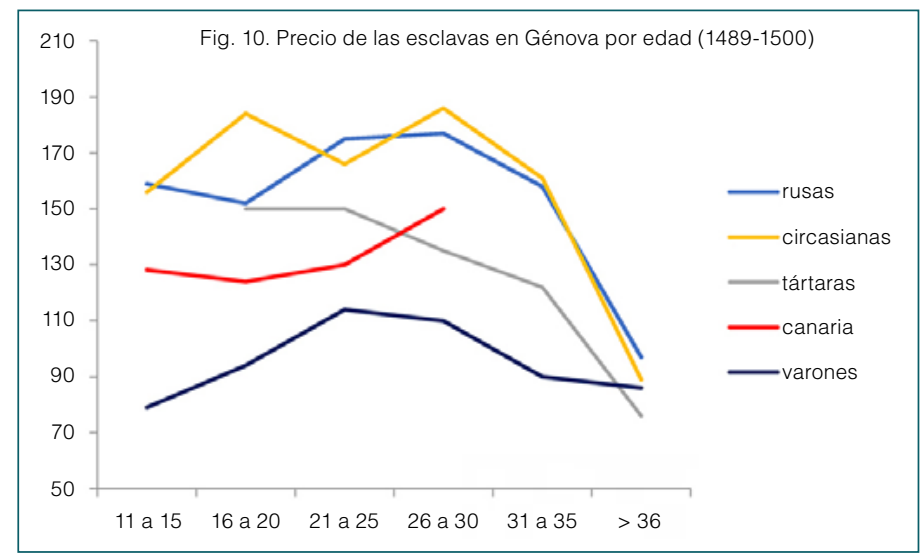

Una situación similar se constata también en el mercado de Andalucía donde, a fines del siglo XV, el precio de las esclavas berberiscas oscilaba entre los $12000 \mathrm{y}$ los 15000 maravedíes, incluso a veces llegaba a superar los 20000 . Las africanas, por su parte, tenían un precio que oscilaba entre los 8000 y los 10000 maravedíes, y casi nunca superó los 12 000, más o menos como el de las canarias. De precio inferior eran solo las indias procedentes del Nuevo Mundo ${ }^{21}$.

En general, sabemos que en Génova los hombres valían menos que las mujeres y que la principal característica que determinaba el precio de las esclavas era la edad, con una mayor valoración por aquellas que tuvieran entre 20 y 30 años (fig. 10). Probablemente, para que se diera esta mayor estimación cumplía un rol fundamental no solo la posibilidad de utilizar por un tiempo más largo los servicios de las mujeres jóvenes, sino también la posibilidad de emplearlas como niñeras o como nodrizas, después de haber tenido un hijo. Si el alquiler normal de una esclava era de 6/10 liras anuales por una nodriza que habet lactem, se podía llegar al doble, como es el caso de una Lucia, alquilada en 1425 por tres ańos por un valor de 60 liras "pro famula et servitrice et nutrice, filiorum suorum dando et ministrando lac suum dictis filiis suis ${ }^{22}$ ».

Como se ve en la fig. 10, el sexo y la edad determinaban una diferencia en el valor entre mujeres y hombres, jóvenes y viejos. Sin embargo, estas características personales no justifican por qué las esclavas rusas valían más que las mauras, y las mauras más que las canarias. Lo cierto es que había una diferencia de precio entre las diferentes etnias. Para explicar este fenómeno se han propuesto dos teorías que se consideran relevantes para la determinación del precio: el color de la piel y las características culturales.

21 Franco Silva, A.: op. cit., p. 31.

22 Tria, L.: La schiavitù in Liguria, Atti della Società Ligure di Storia Patria (1947) p. 170. 


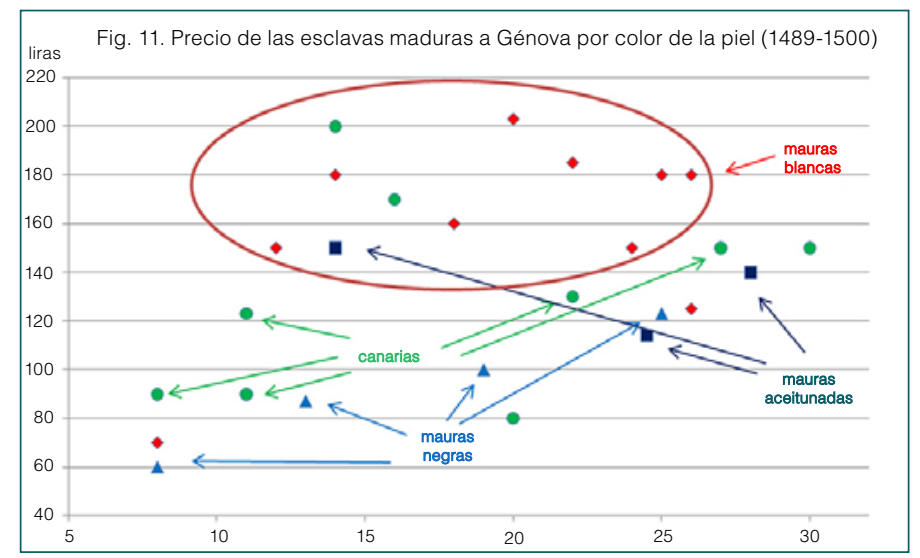

En lo que se refiere al color de la piel, sabemos que en Italia las esclavas de tez negra valían menos que las de tez blanca. Un ejemplo es la venta en Florencia de unas esclavas enviadas desde Portugal por Giovanni Guidetti en 1474 y en 1476, las seis registradas en los actos de venta como nera se cotizaron a solo 37 ducados, mientras que las seis «bianca» se vendieron a 56 .

También en Génova se encuentran similares diferencias en los precios: en 1495 la mora alba Isabella de 21 años se cotizó a 200 liras, mientras que al año siguiente la mora nera Margherita de 25 años se vendió por 123. Y en 1497 una mora alba de 20 años fue vendida a 203 liras, más del doble que las 100 liras de la maura nera María de 19 años.

Para confirmar la validez de esta teoría se han comparado los precios de las esclavas mauras y canarias vendidas en Génova entre 1460 y 1500. Como puede verse en la figura 11, la cotización de las esclavas mauras registradas en las actas notariales como de tez «bianca» es siempre muy superior a las «olivigna» (aceitunadas) y a las "nera», y las canarias se ubicaban más cerca del precio de estas últimas que de las blancas.

Teóricamente, el color de la piel no debería haber influido en el precio de las esclavas canarias, quienes eran caucásicas de tez clara como cualquier otra espańola ${ }^{23}$. Por ejemplo, los 43 cautivos canarios presentados a la Bailía General de Valencia, de los cuales se especificaba el color de la piel, fueron todos registrados como cautivos blancos y ninguno como cautivo negro, término que se reservaba para los esclavos de Berbería.

${ }^{23}$ Vieira y Clavijo (1700) relatan que asumían el mismo color tostado de los canarios también los españoles recién llegados a la isla de Tenerife: «... si bien los guanches que habitaban hacia las partes meridionales de la isla eran de una tez bastantemente tostada, como lo son en el día cuantos espańoles moran en ellas, no por eso dejaban de ser blancos, rubios y de buena presencia los que vivían en los distritos del Norte». 
Para sortear esta aparente contradicción de unas esclavas de tez blanca que cotizaban como las esclavas de tez negra hay que tomar en cuenta que, como señalan varios cronistas, muchas mujeres canarias lucían una tez tostada y morena debido a la exposición a los intensos rayos solares típicos de las islas ${ }^{24}$.

Considerando que las esclavas canarias muchas veces llegaban a Génova directamente desde el Archipiélago ${ }^{25}$, es posible que los compradores genoveses confundieran el bronceado temporal provocado por el sol con una pigmentación oscura permanente. Podría ser este el caso de la esclava que, como se ha visto, llegó en 1496 directamente (ad dricturam) desde Valencia. Como relata el viajero alemán Jeronimo Munster, quien en 1494 tuvo la oportunidad de ver en Valencia a los esclavos canarios recién llegados desde Tenerife: «vi en una casa hombres, mujeres y niños que estaban en venta [...]. Son muy morenos, pero no negros ${ }^{26}$.

Algo similar pasaba en Florencia a finales del siglo xiv, donde los esclavos griegos en su mayoría eran registrados como de tez aceitunada (olivastra) y no blanca $^{27}$.

El segundo aspecto que indudablemente influía en el valor de las diferentes etnias eran las características culturales y comportamentales. En Italia a cada grupo étnico se le reconocían cualidades y defectos específicos, como explica en una carta a su hijo la noble dama florentina Alessandra degli Strozzi: «las (esclavas) tártaras soportan mejor la fatiga y son más rudas. Las rusas son de aspecto más delgado y

${ }^{24}$ Edmund Scory (1526): «Los naturales que habitaban en la banda sur de la isla eran del color de la aceituna, pero los que vivían en la banda del norte eran rubios, especialmente las mujeres, y tenían el pelo liso y brillante». Edmund Scory: «Extracts taken out of the Observations of the Right Worshipfull Sir Edmond Scory», en Quartapelle, A.: op. cit., p. 171. Alonso de Espinosa (1594): «Es esta gente (los de la banda del Sur) de color algo tostada y morena, agora sea por traer este color de generación, agora sea por ser la tierra algo cálida y tostarlos el sol, por andar casi desnudos, como andaban. Más los de la banda del Norte eran blancos, y las mujeres hermosas y rubias y de lindos cabellos». Alonso de Espinosa: «Historia de Nuestra Señoras de Candelaria», en QuarTAPelle, A.: op. cit., p. 340. Abreu Galindo (1632): «A los naturales de esta isla llaman guanches los que la conquistaron; era gente de mediana estatura. Los de la banda del sur son muy morenos, y los de la banda del norte son blancos y rubios en cuerpo y cabellos» Abreu Galindo: «Historia de la conquista de las siete islas de Gran Canaria», en Quartapelle, A.: op. cit., p. 428. Juan Núñez de la Peña (1666): «Los que habitaban a la banda del Sur, eran de color algo tostada y morena, y los de la banda de Norte eran blancos y rubios, como hoy se experimenta en los que nacen y se crían de las partes de Guimar, Arico, Chasna y sus términos que son al Sur algo morenos, de color trigueńos, y los que nacen en Taganana, y sus términos que es al Norte, blancos y rubios». Núnéz de la Peña: "Conquista y antigüedades de la isla de la Gran Canaria», en Quartapelle, A.: op. cit., p. 484. Marin y Cubas (1687): «Los guanches son medianos de cuerpo los de Taoro, que es hacia la parte del norte son blancos y rubios de cavellos; los de Adexe a la del sur son prietos, y cavello negro...». Tomás Arias Marín de Cubas: «Historia de las siete islas de Canaria», en Quartapelle, A.: op. cit., p. 541.

${ }_{25}$ Gioffrè, D.: «Il commercio d'importazione genovese alla luce del registro dei dazi 1495-

1537», en Studi in onore di Amintore Fanfani, Gioffrè Editore (1962), vol. 5, p. 144.

${ }^{26}$ Munster, J., en Quartapelle, A.: op. cit., 204.

27 Boni, M.: La domesticité en Toscane aux XIV et XV siècles, Thèse de doctorat Univ. Genève (2006) p. 252. 
son más bellas, pero, a mi parecer, son mejores las tártaras. Las circasianas tienen la sangre fuerte y, sin embargo, esta característica es común a todas $»^{28}$.

La importancia que se atribuía en Italia a los aspectos culturales para determinar el valor de las esclavas se explica al considerar que muchas veces las familias recurrían a las esclavas cuando no encontraban mano de obra libre dispuestas a trabajar a cambio de un salario. En muchas oportunidades, hasta en las actas oficiales, para referirse a una "esclava» se utilizaba el termino serva o ancilla ${ }^{29}$, como es el caso de la joven sclava et serva Anna de 14 ańos de progenie maurorum canarie, vendida por Francesco Cibo en 1498, o como Caterina de partibus canarie, de la misma edad, serva seu ancilla de Giovanni de Bichi de Siena, en 1489. Ciertamente, las jóvenes esclavas que cumplían la función de servidoras ${ }^{30}$ sin salario, compartían el día a día de la vida de los dueños, ya que vivían con ellos en la misma casa y llegaban a ser consideradas como un miembro más de la familia ${ }^{31}$, incluso podían llegar a seguir viviendo en la casa de sus amos después de la manumisión que, en el $85 \%$ de los casos, se concedía antes de los 45 años $^{32}$. En relación con esta «esclavitud temporal», cuando se compraba una esclava que no se encargaba solo de la limpieza de la casa y de las labores más pesadas, sino también del cuidado de niños y ancianos, se prestaba atención a su cultura y a su posibilidad de integrarse a la familia ${ }^{33}$.

Que los aspectos culturales tuviesen importancia en la determinación del valor del esclavo lo certifica también la experiencia espańola, en la que el precio de los esclavos africanos variaba en función de su clasificación como bozales o ladi$n o s^{34}$. En un sentido estricto, el termino bozal se utilizaba para los esclavos recién

28 "Qualche tartera di nazione, che sono per durare fatica vantaggiate e rustiche. Le rosse, cioe quelle di Russia, sono più gentili di compressione e più belle, ma, a mio parere, sarebbero meglio tartere. Le circasse è forte sangue, benché tutte l'abbino questo». STrozzI, A.: Lettere di una gentildonna fiorentina del secolo XV. Ed. Sansoni, Firenze (1877) p. 475.

${ }^{29}$ Heers, J.: "Esclaves et domestiques au moyen-Age» Fayard 1981, p. 159.

${ }^{30}$ Cluse, C.: Femmes en esclavage: quelques remarques sur L'Italie du nord (XIV-XVE Siecles, Medieval Mediterranean Slavery, 2008, p. 4.

${ }^{31}$ Origo, I. op. cit., p. 340.

32 Heers, J.: «Esclavos y sirvientes en las sociedades mediterráneas durante la edad media», Valencia 1989 p. 69, en IzQuIERDo: op. cit., p. 246. Muchas veces se recorría a la manumisión también porque el mantenimiento de un esclavo era costoso: el Catastro de Florencia de 1427 calcula que el costo anual era de 14 florines cuando el precio de compra era de 30/50 florines por un varón y de 60/70 por una hembra. Tomoko TAKAHASHI: Il rinascimento dei trovatelli: il brefotrofio, la città e le campagne nella Toscana del XV secolo», Edizioni di storia e letteratura, Roma 2003, p. 55. El esclavo hacia parte de la familia, hasta bastante más que el trabajador asalariado que transcurría su vida pasando de una familia a otra. Tampoco el trabajo de estas «servidoras sin salario» era totalmente sin remuneración: los amos les proporcionaban techo, vestidos, calzados y, sobre todo alimentos por lo que, en épocas difíciles, incluso despertaron la envidia entre muchas mujeres libres. IzQuierdo, op. cit., p. 246.

33 En las ciudades españolas y portugueses este «concubinato» con esclavas de origen africano en muchos casos ha llevado al mestizaje. En Italia, donde la casi totalidad de las esclavas son orientales y «blancas», el fenómeno es mucho menos visible. HeErs, J: Estudes sur les estructures...», op. cit.

${ }^{34}$ Victor Hugo Haro Hidalgo «Precio de los esclavos en el Perú: 16 50-1 820», LimaPeru 2017. Tesi doctoral -Pontificia Universidad Católica del Perú- Facultad de ciencias Sociales, p. 51. Aurelia Martín Casares: La esclavitud en la Granada del siglo XVI: género, raza y religión, Edi- 
traídos de África, pero a veces también para los canarios ${ }^{35}$, ya que indicaba que no hablaban otra lengua que la propia y que por esto no eran capaces de entender y de comunicarse ${ }^{36}$. En un sentido más amplio, sin embargo, el término subrayaba la distancia no solo lingüística, sino también cultural de los recién llegados, cuyos hábitos eran muy distintos de los de los españoles. Cuando el esclavo se culturizaba y se latinizaba, de bozal se convertía en ladino $0^{37}$ y su precio aumentaba: en Granada, por ejemplo, el precio de un bozal era de 24,4 ducados, el del medio ladino subía a 27,8 y el del esclavo o de la esclava ladina que tenía conocimiento de la cultura y de la lengua castellana ascendía a 31,6 ducados ${ }^{38}$.

En Italia del norte los términos bozal y ladino no fueron utilizados nunca. Sin embargo, puede suponerse que la lejanía/cercanía cultural de las diferentes etnias respecto de la italiana fue utilizada como parámetro para determinar su precio, atribuyendo un valor inferior a las etnias cuya cultura fuera totalmente diferente, mientras que los grupos que compartían un patrimonio cultural común tenían un valor más alto.

Si la lejanía cultural fue un parámetro utilizado para determinar el precio de las esclavas, no debe extrañar la baja cotización de las esclavas canarias. No hay que olvidar que, como nos han transmitido los cronistas de la época, a finales del siglo $\mathrm{xv}$ el grado de cultura en las islas era prehistórico ${ }^{39}$ y que sus habitantes iban casi desnudos, apenas vestidos con pieles y sin zapatos, habitaban en cuevas, no conocían los metales, el dinero o la rueda, momificaban a los muertos y adoraban al sol y la luna.

torial Universidad de Granada, Campus Universitario de Cartuja, 2000, p. 232. Meisel Roca, A. y Granger Serrano, A.: «Determinantes del precio de los esclavos en el caribe neogranadino en el siglo XVIII", Tiempo \& Economia 6 (2019) pp. 143-159 (bozales mas caros).

35 En Valencia el término bozal se utilizó por ejemplo en el caso de Caterina de 7 años: «No jura com fos menor ni menys fonch intorroguada com fos molt boçal e nos pogues interrogar per altres catives com fos de altres parts e terres de Canaria», en Blumenthal, D.: op. cit. p. 42.

36 Otros lingüistas opinan que bozal deriva del nombre de la traba de cuero que se aplica en el hocico de ciertos animales para que no muerdan. Un animal con bozal es de naturaleza bravía y agresiva; igualmente el africano bozal tampoco está domesticado y conserva un resto de su albedrío, de su arisca personalidad reacia a la servidumbre.

37 Granada-Casares Martin, A.: La esclavitud en la Granada del siglo XVI. IzQuierdo Labrado, J.: «La esclavitud en Huelva y Palos a fines del siglo xv, Huelva en su historia-2, p. 63.

${ }_{38}$ En las colonias de Suramérica esta diferencia de precio a favor de los «ladinos» continua hasta el siglo XVI. A partir del siglo XVII los propietarios empiezan a apreciar y pagar más los «bozales» que se consideraban más obedientes y menos capaces de defender sus derechos.

39 Aznar Vallejo, E.: «El encuentro de las culturas prehistóricas canarias con las civilizaciones europeas», X Coloquio de Historia Canario-americana (1994). 


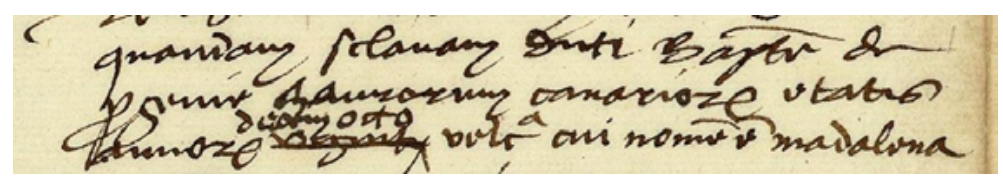

Fig. 12. Sclava Maddalena de progenie maurorum canariorum.

\section{PEQUEÑAS Y GRANDES HISTORIAS DE ESCLAVITUD}

Los documentos italianos no se limitan a ofrecernos números útiles para las estadísticas del fenómeno esclavista. Muchas veces nos cuentan, sin quererlo, pequeñas y grandes historias y nos ofrecen detalles útiles para comprender la vida, la forma de pensar y actuar de las sociedades italianas de la época.

Este es el caso de la canaria Caterina, de edad desconocida, quien fuera dejada por el genovés Barnaba Carrega como testamento a su esposa en 1496. Los esclavos eran una "propiedad" como cualquier otra y en los inventarios de los bienes de los difuntos se encontraban en listados junto con muebles, ropas y hasta con gallinas y mulas. Por cierto, disponer mortuis causa a favor de la propia esposa de una "propiedad» valiosa como una esclava garantizaba a la viuda una doble protección. No solo un capital, que podía ser monetizado ventajosamente en cualquier momento, sino también la posibilidad de alquilarla para conseguir una no despreciable renta anual.

Como todos los «bienes», los esclavos eran objeto de un comercio que veía involucradas a grandes familias y a pequeños mercaderes. Desde Génova las esclavas y esclavos no salían solo hacia la península ibérica. En algunas oportunidades, los mercaderes genoveses enviaban su mercancía humana también hacia Toscana y Sicilia. En enero de 1487, el boticario Battista Valle entrega a Antonio Pinu la esclava Maddalena de progenie maurorum canariorum (fig. 12) de 16 ańos para que la transporte a Sicilia a su riesgo (risico, periculo et fortuna Dei, mari et gentium) para venderla, hacer trueque o permutarla con el máximo provecho.

Siete meses después, al no tener mayores noticias del resultado de la transacción, el Valle otorga una procura a un Marco Cabella para que viaje a Sicilia y recupere la esclava o el dinero de su venta. Los escritos no aclaran cuál fue el destino de Maddalena, si quedó en Sicilia o si regresó a Génova. Lo único que sabemos es que, pocos meses después, en el inventario de los bienes del recién difunto Valle no aparece ni el dinero ni la esclava Maddalena.

a) Caterina, la esclava vendida dos veces (doc. 3)

Mayores detalles tenemos de la historia de una Caterina de progenie canariarum de 28 años, quien en principio fue vendida por Bertuchia Odorico a Marco Benci de Siena por 47 ducados en 1495. Dos años más tarde, Caterina, quien en ese momento tenía cerca de treinta años, aparece en otra acta de venta. $Y$ finalmente es 
otro prominente ciudadano de Siena, el banquero Matteo Salvi, quien la vende por 50 ducados a un ciudadano de Savona, ciudad cerca de Génova ${ }^{40}$. En el acta notarial se especifica que Caterina es vendida ad habendum, tenendum et gaudendum, fórmula que se ha querido interpretar con una connotación sexual ${ }^{41}$. En realidad, la expresión ad guadendum, que erróneamente ${ }^{42}$ parecería indicar que el comprador estaba autorizado a disfrutar de los «favores sexuales» de la esclava, era una fórmula común que se utilizaba en Italia también en el caso de esclavas pequeñas como Ana de progenie maurorum canarie de 14 años en 1498 o, en 1474, de Caterina de 10 años ${ }^{43}$, y hasta en la venta de bienes muebles, como la biblioteca de Giovanni Traversagno en Génova en $1458^{44}$.

Además, incluir en un contrato que la mujer esclava tenía que estar sexualmente a disposición de su dueño era un detalle inútil, pues todo lleva a pensar que, especialmente en las ciudades del centro norte de Italia, la mayor presencia de esclavas que de esclavos, así como el mayor precio que se pagaba por ellas, respondía a una explotación sexual generalizada, sistemática y socialmente consentida ${ }^{45}$ al punto que se ha supuesto que en la sociedad italiana medieval la cohabitación, y la mentalidad de la época puede haber llegado a tolerar, dentro de las familias, alguna

40 ASSiena, Carte Salvi, 14 maggio 1487 «... unam sclavam, nomine Caterina, de progenie Canariarum, etatis annorum triginta vel circa, sanam et nitidam, secundum consuetudinem civitis Ianue, ad habendum, tenendum et gaudendum dicta sclava...», en PrUnAJ, G.: Notizie e documenti sulla servitù domestica nel territorio senese secc. VIII-XVI, Bullettino Senese di Storia Patria 1936 fasc. IV, pp. 425-430. En Savona los esclavos entre el 1460 y el 1480 habían llegado a ser el $25 \%$ de la población.

${ }^{41}$ Por ejemplo, por Charles Verlinden «le terme gaudendum ajoute une note inhabituelle et de couleur incontestablement licencieuse», en VerLINDEN, C: "L'esclavage dans l'Europe médiévale» 1955, vol. 2, p. 389.

42 Dèbax, H.: "Les sociétés méridionales à l'age féodal: Espagne, Italie et sud de la France, $X^{\mathrm{e}}$ XIII siecle» CNRS 1999, p. 113.

43 En la venta en Génova de la esclava Caterina de progenie maurorum alborum di 10 años en 1474, el notaro Tommaso Duracino utiliza la fórmula: «sanam et nitidam ab omnibus viciis et magagnis occultis et manifestis, secundum morem et consuetudinem civitatis Janue. Ad habendum, tenendum, gaudendum, possidendum, usufructuandum, vendendum et alienandum». En el manuscrito Carte Staglieno, vol. 4, pp. 55-57. Por cierto, en algunas pocas oportunidades, los actos notariales registran de forma explícita el derecho del dueño de disfrutar sexualmente de la esclava, como en el caso del contrato de alquiler de una joven esclava a Génova en 1420 donde el notario apunta que la esclava tiene el deber de servir su nuevo dueño no solo en la mesa sino también «en la cama, de acuerdo a su voluntad».

${ }^{44}$ Petti Balbi, G.: Governare la città'. Pratiche sociali e linguaggi politici a Genova in età medievale, Firenze University Press (2007), p. 240.

45 Stella, A.: «Des esclaves pour la liberté sexuelle de leurs maitres (Europe occidentale XIV XVIII $^{\mathrm{e}}$ siecles», Clio, Histoire, femmes et sociétés, pp. 191-209. El estatuto del siglo XIII de la ciudad de Albenga, cerca de Génova, que punía con una enmienda de 2 florines de oro quien importunaba una esclava con palabras deshonestas, puede razonablemente motivarse con el deseo de proteger el dueño en su derecho de no ser molestado en su relación sexual «exclusiva» con su esclava. Cluse, C.: "Femme en esclavage: quelques remarques sur l'Italie du Nord (XIV -XV ${ }^{\mathrm{e}}$ siècles)», online in Medieval Mediterranean Slavery: Comparative Studies on Slavery and Slave Trade in Muslim, Christian and Jewish Societies (8th-15th centuries) May 2008, p. 11. 
forma de concubinato entre amo y esclava ${ }^{46}$. Así describe la situación el poeta florentino Pucci a finales del siglo XIV: «La esclava tiene ventajas en todo ... no tiene el anillo de bodas al dedo, pero satisface los apetitos (sexuales) del marido mejor que su esposa y con eso le da jaque mate» ${ }^{47}$.

Como puede imaginarse, no todas las esposas italianas aceptaban de buen grado este tipo de competencia. Por ejemplo, en una carta al florentino Francesco Datini de 1393 se lee: «Doña Paparo se queja mucho con Ud. y sobre todo con vuestra esposa doña Margherita porque ha permitido que Ud. vendiera a su familia una esclava tan joven y tan bella. Las mujeres deberían guardarse de hacer cosas similares las unas a las otras ${ }^{48}$. Y en otra carta monna Leonarda le pide a su intermediario en Génova que «no compre una esclava demasiado linda, para evitar tener que hacerle alguna maldad». También los hombres veían que las esclavas eran un riesgo para la paz familiar, así Francesco Datini llega a decir de una esclava: «Me han dicho que es una puta, y yo sé cómo actúa esta clase de mujeres $»^{49}$. Y Vanno Sacchetti se dirige en una carta a uno de sus clientes tranquilizándole: "He comprado para Ud. una joven esclava de 10 o 12 ańos, con una cara aplastada como un tablón de madera: estoy seguro de que vuestra esposa Margherita no se pondrá celosas ${ }^{50}$.

La profusión de estos amores ancilares, además de lo relacionado con la lujuria de los italianos, tenía probablemente una justificación demográfica: en Florencia en 1426, el censo de los habitantes revela que en la franja etaria que iba de los 18 a los 32 ańos se contaban solo 100 mujeres por cada 132 varones $^{51}$.

La promiscuidad sexual dentro de las familias a veces dejaba consecuencias indeseadas: de los 7534 gettatelli (niños abandonados) llevados a los orfanatos

${ }^{46}$ Heers, J.: «Le Clan familial au Moyen Âge: Étude sur les structures politiques et sociales des milieux urbains", Presses Unversitaires de France, 2018. La frecuencia del mestizaje entre blancos y negras hacer pensar que el concubinato fuese probablemente aceptado y tolerado también en Sevilla. Franco Silva, A.: La esclavitud en Sevilla y su tierra a fines de la Edad Media, Excma. Diputación Provincial de Sevilla, 1979, p. 139. Las relaciones sexuales con las esclavas tenían que ser tan habituales que los Estatutos Civiles y Criminales de Génova de 1375 estatuían que el hombre libre que hubiera embarazado la esclava de otro estaba obligado a pagar a su amo la cantidad de 25 liras, otras 50 si la mujer moría como consecuencia del parto y tenía que proveer al niño. Si el responsable era un esclavo se le aplicaba la cantidad máxima y si no podía pagar se le cortaban las orejas. Se aplicaba la pena máxima de 50 liras también si el padre vivía en la casa del amo. El concubinato del amo con su propia esclava no estaba prohibido y el nacimiento del hijo no rendía libre la esclava. «Schiavi a Genova...», op. cit., p. 142.

${ }^{47}$ Pucci, A.: «Le schiave hanno vantaggio in ciascun atto [...] non ha per matrimonio anello in dito, -ma ella appaga me' suo appitito- che la sua donna, a cui dà scaccomatto».

48 Pacini: «Studi di storia economica toscana nel Medioevo e nel Rinascimento in memoria di Federigo Melis» Pisa (1987), p. 304.

49 "no tolla troppo bella, a ciò no ne faciessi chattività" $\mathrm{y}$ «e' me' detto ch'ell'è una troia, $\mathrm{e}$ io so que che son le lori pari», en SAnsoni, G.C.: Studi Di Filologia Italiana, vol. 8, p. 322.

50 «v'ho comprato una schiavetta d'anni 10 o 12, c'ha un viso come un tavolaccio: so bene monna Margherita (su esposa) no ne piglierà gelosia», en BiraL, P.: Puer ludens: giochi infantili nell'iconografia dal XIV al XVI secolo, (2005), p. 21.

51 Hesse, J.: 1981, op. cit., p. 215. 


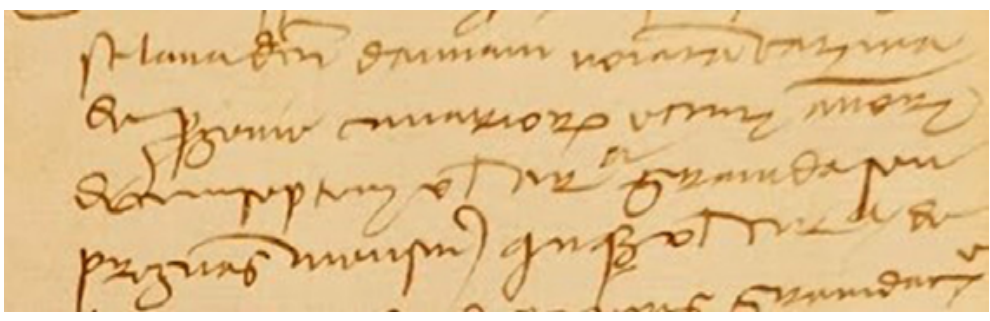

Fig. 13. Cazina, de progenie Canariorum, etatis annorum decem septem vel circa, gravida seu pregnans mensium quinque vel circa.

de Florencia entre 1372 y 1485, más de 1000 eran el fruto de la relación entre una esclava y su dueño, un miembro de la familia u otro hombre libre, muchos de los cuales pertenecían a las más poderosas familias de Florencia, como los Medici, los Strozzi y los Albizzi ${ }^{52}$. Contrariamente a lo que pasaba en España, en la mayoría de las ciudades italianas el hijo de un hombre libre y de una esclava heredaba el estatus del padre y nacía libre ${ }^{53}$. Por lo tanto, el cabeza de familia podía llegar a querer que desaparezca de su casa no solo un hijo bastardo, sino un bastardo hijo de una esclava.

Las jóvenes esclavas, sin embargo, no despertaban el interés sexual solo del amo y de los varones de la familia, sino también de los otros hombres. Para proteger al dueño por el daño económico que podía derivar de un embarazo indeseado los Statuti Civili e Criminali de Génova de 1375 estatuían que el hombre libre que hubiera embarazado la esclava de otro estaba obligado a pagar a su amo la cantidad de 25 liras y otras 50 si la mujer moría como consecuencia del parto, y tenía que proveer al niño $0^{54}$.

A partir del siglo $\mathrm{xv}$, para proteger al dueño contra el riesgo de perder un «bien» tan valioso como una esclava, se difunde en Génova y en Barcelona un peculiar contrato, el seguro contra el riesgo del parto que, con el pago de una prima, garantizaba al dueño el valor de la esclava si se enfermaba o moría como consecuencia del parto. Así, en 1466, Damiano de Franchi asegura la esclava canaria Caterina de 17 años al quinto mes de embarazo por la no despreciable cantidad de 175 liras (doc. 5).

52 Boni, M.: op. cit.

53 McKeE, S.: "Inherited Status and Slavery in Late Medieval Italy and Venetian Crete" Past \& Present, No. 182 (Feb., 2004), pp. 31-53. Por Florencia: Origo, I.: «The Domestic Enemy: The Eastern Slaves in Tuscany in the Fourteenth and Fifteenth Centuries» Speculum, vol. 30 , n. 3 (Jul., 1955), p. 364, n. ${ }^{\circ} 113$.

54 Penas similares se aplicaban en otras ciudades italianas: en Venecia desde 1344 se tenía que refundir el dueño; en Florencia se obligaba a pagar una tercera parte del valor de la esclava para su supuesto «deterioro»; en Lucca, desde 1372, no solamente se condenaba el padre a una sanción 100 liras sino además a tomar con si la esclava y, si el amo quería venderla, a refundir el doble de su valor. ZANELLI, A.: Le schiave orientali in Italia nei secoli XIV e XV, Arnaldo Forni Editore (1885) p. 61. 
Volviendo a la historia de Caterina, en el acto de venta se utiliza también la expresión sana et nitida, que ha sido interpretada en el sentido de que Caterina era «virgen» y que su valor era, por este motivo, más alto que lo usual ${ }^{55}$. En realidad, la especificación sana et nitida quiere decir simplemente que Caterina gozaba de buena salud (sana ab omnibus viciis et magagnis occultis) ${ }^{56}$. Declarar las enfermedades de la esclava o del esclavo era, en efecto, una obligación del vendedor, y eventuales omisiones podían comportar la resolución del contrato. Para cautelarse de las posibles quejas del comprador no era raro encontrar esclavos de los que se declaraba que eran vendidos cum tigna, sine capillis, cum fetore in naso o cum uno oculo. Para cautelarse, el comprador podía también obligar al vendedor a excluir algunas enfermedades específicas, como es el caso del esclavo canario Martinicus de generatione canaria, vendido en Venecia en 1498, del cual se especifica que es sine defectu caduci morbi vel aliis defectibus, o sea que no sufre de epilepsia y que no tiene otros «defectos" ${ }^{57}$. La introducción de cláusulas para proteger al comprador de eventuales enfermedades del esclavo no era una prerrogativa solamente italiana: por ejemplo, en 1499, en la venta en Barcelona de la esclava canaria Caterina de 18 años el vendedor garantiza que no sufre de epilepsia, demencia y enuresis, es decir, que no se orinaba en la cama ${ }^{58}$.

En alternativa, el esclavo podía también ser vendido sin ninguna garantía pro talis qualis est o con omnibus suis magagnis, circunstancia no sin efecto en el precio: por ejemplo, en 1497, en Génova, la esclava maura Maria de 19 años fue vendida sin garantía a 100 liras, mientras que otra esclava de la misma progenie y edad, pero sana et nitida, se cotizó a 203 liras ${ }^{59}$.

b) Otra Caterina, de esclava a mujer libre (doc. 3)

También existe una cuarta historia de una esclava canaria que tiene lugar en Siena entre 1485 y 1489, pero esta vez con un final feliz. La protagonista es otra Caterina, de 14 años, vendida por 52 ducados a Johannes de Bichi. En el acta de venta se indica que Caterina es hija de Hyse, de Sala, de partibus Cannarie, lo que parece indicar que su procedencia es de la Isla de Sal en el Archipiélago de Cabo Verde. En el momento del descubrimiento, las Islas de Cabo Verde estaban despobladas y para su explotación se procedió a importar esclavos africanos Jolof. El caso de Caterina podría indicar que, en una primera fase, se transfirieron también esclavos desde las Islas Canarias, como se hizo posteriormente también en Madera.

55 "Conferenze di Federico Melis ed altri» Società Storica della Valdelsa, 1979, p. 58.

${ }_{56}$ Por varios ejemplos ver TRIA op. cit., pp. 80, 81, 101, 155, 190, 200, 202, 204, etc.

57 Entre los posibles «defectos» de un esclavo o de una esclava se incluya el estar embarazada o, por lo contrario, no tener menstruaciones (de carencia menstruorum), mear en la cama (de mingendo lectum), ser idiota (de stulticia).

58 Armenteros Martínez, I.: La esclavitud en Barcelona a fines de la Edad Media (14791516), Universitat de Barcelona 2012, p. 1030.

59 Gioffre, D.: op. cit., p. 125. 
En los escritos se especifica que Caterina tenía una marca de color casi verde en la barbilla y una pequeña cruz debajo del ojo derecho ${ }^{60}$. La descripción de las características físicas de un esclavo en el acta de venta no debe extrañar, pues los escritos se utilizaban probablemente como una especie de documento de identificación. En las actas estipuladas en Toscana, aunque no en las genovesas, era normal encontrar descripciones detalladas que incluían, además de cicatrices, lunares, signos de viruelas, también el color de la piel (alba, clara, rubea, bruna, ulivigna), color y forma de los ojos (chiari, neri, grossi, parvi, suffornati) y forma de la nariz (parva, grossa, curta, schiacciata, rincagnata, affilata) ${ }^{61}$.

Seis años más tarde, Caterina, quien en ese momento tenía 20 años, volvió a ser protagonista de un acta notarial cuando, en 1496, su dueño Johannes de Bichi decidió donarle la libertad.

La manumisión no era un acontecimiento excepcional en Italia donde la esclavitud se consideraba raramente una condición de por vida.

Dos eran las principales formas de manumisión de un esclavo: en la primera el amo donaba la libertad pro anima et in remissione peccatorum, o sea, por la salvación de su alma y por el deseo de ganarse la indulgencia divina. La manumisión tomaba la forma de un legado testamentario que obligaba a los herederos a liberar el esclavo en el momento de la muerte del dueño ${ }^{62}$. La segunda forma era in premium servitutis, es decir, como premio por los buenos servicios prestados por el esclavo. En este caso, la forma de donar la libertad era un contrato que preveía la posibilidad de poner condiciones y podía ser revocada por ingratitud o por inobservancia de las condiciones contractuales.

En el caso de Caterina, Johannes de Bichi la manumite maxima sui animi liberalitate convencido de que, como especifica el contrato, «tanto los hombres como las mujeres nacen líberos» ${ }^{63}$. La libertad donada por Bichi es también un agradecimiento por sus servicios (in premio sue servitutis). Para garantizarle a Caterina un futuro sin problemas económicos, en el mismo acto Bichi casa a Caterina con el «hombre libre» Cola Gobite, un manumiso ex partibus indianis, y constituye a su favor una dote de cincuenta ducados. A cambio de su libertad, Caterina y su esposo se obligan a servir Johannes Bichi y a sus herederos por 15 años sin pretender ningún sueldo (sine aliquo pretio, premio vel mercede).

60 "cum signo in mento coloris quasi viridis et cum una parva cruce in facie sub oculo dextero». Charles Verlinden se pregunta si podría ser el rastro de las pintaderas. Verlinden, C. op. cit., p. 19.

${ }^{61}$ Boni, M.: op. cit., p. 253.

${ }^{62}$ Como ejemplo de manumisión "pro salvatione animae» se puede citar el caso del viajero veneciano Marco Polo que en su testamento de 1323 escribe: «absolvo Petrum famulum meum de genere Tartarorum ab omni vinculo servitutis ut Deus absolvat animam meam ab omni culpa et peccato». Zambroni, F.: Gli Ezzelini, Dante e gli schiavi, Vienna, 1870, p. 238. «Los Statuti di Genova de 1498 prohibieron la manumisión por testamento por temor que el esclavo matara a su dueño para obtener la libertad", en PrunaI, G., op. cit., nota 6, p. 250.

63 "quo omnes tam mares quam femine nascebantur liberi». 


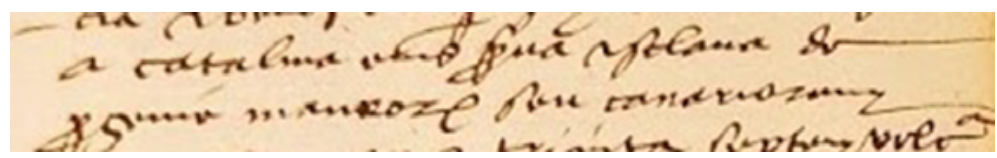

Fig. 14. Catalina, eius serva et sclava de progenie Maurorum seu Canariorum.

El matrimonio de una esclava con un hombre libre o, como en este caso, con un esclavo manumiso, no era un fenómeno raro en Italia y tenía como objetivo garantizarle a la esclava un futuro sin problemas económicos. Menos frecuente era que se liberaran esclavas de solo 20 años, o sea, cuando su valor económico era el máximo. Por lo tanto, la temprana edad de Caterina hace sospechar que su manumisión podría haber encubierto el escándalo de un embarazo indeseado, fruto de la relación entre Caterina y su dueño Johannes de Bichi.

La condición aceptada por Caterina y su esposo Cole Gobita de seguir sirviendo por 15 ańos a su antiguo dueño a cambio de la manumisión, esto es, en total treinta años, era más gravosa de lo habitual pero no excepcional ${ }^{64}$. Por ejemplo, en 1490 en Barcelona, el mismo día en que lo compra un curtidor de piel se compromete a liberar al esclavo Joan, blanco, sarraceno, canario, de aproximadamente 18 años, si le sirve con fidelidad durante 14 años y si, durante ese tiempo, no trata de escapar y no juega a los dados o a cualquier otro juego sin su permiso. En Génova se registran también casos de esclavos manumisos a condición de que sigan sirviendo a su dueño. En 1488, a Caterina de progenie Maurorum seu Canariorum, se dona la libertad a condición que sigua sirviendo su ama para toda la vida ${ }^{65}$ (doc. 4).

Para entender por qué los esclavos aceptaban una condición tan cara para reconquistar su libertad hay que considerar que el esclavo era una persona sin el mínimo derecho: el amo podía infligirle cualquier punición (ius corrigendi) y hasta podía matarlo, con la única limitación de no utilizar armas; podía ponerle un collar de hierro con una campanita o grillos en los tobillos. El esclavo no podía contraer matrimonio sin el permiso del amo; podía recibir donaciones y poseer dinero, pero el amo tenía derecho a retenerlo en caso de venta o manumisión; no podía oponerse a ser vendido o alquilado, como sucedió con el canario Janicho de 30 años quien estuvo rentado por 8 ańos a Giovanni Salvago, en 1471. Por el contrario, la manumisión extinguía todos estos vínculos y devolvía al esclavo su condición de persona libre que podía estipular contratos y asumir obligaciones, testar, donar y hacer valer sus derechos en los tribunales ${ }^{66}$.

\footnotetext{
${ }^{64}$ Normalmente $6 / 8$ anos.

${ }^{65}$ A este contrato se añade la condición que, en caso de muerte de la dueña dentro de quince años, Caterina seguirá sirviendo la nieta por cinco ańos.

${ }_{66}$ Olgiati, G.: "La città è piena di schiavi: la condizione servile a Genova nel medioevo" in «Schiavi a Genova e in Liguria» Sagep, 2018, pp. 34-35.
} 


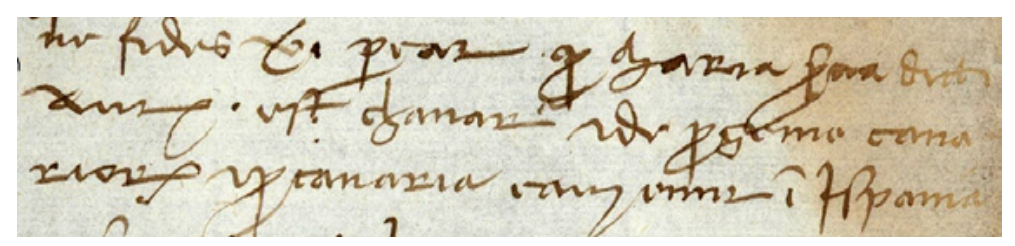

Fig. 15. Maria, serva dicti Antonii (de Bargaglio), est chanaria et de progenie canariorum.

c) María, la esclava de la isla Gomeria (doc. 2)

La última historia es de 1481 y tiene como protagonista a María y a su dueña, Caterinetta da Bargagli, que quería demonstrar que procedía de las Islas Canarias. Frente a las autoridades deponen tres testigos, entre ellos está Tedosio Lercaro, que declara que en 1478 el navío de Napoleone Cigalla, en el que estaba embarcado, fue empujado por una tormenta a una de las Islas Canarias llamada Gomeria. Allí fue capturado y tenido como prisionero por algunos meses «sub potestate» del señor de la isla Diego Erreri (Diego de Herrera), caballero de Sevilla y señor de aquellas islas. Mientras duró el cautiverio, el testigo vio a la esclava canaria María servir en la casa de la hija de don Diego (María de Ayala).

El testigo recuerda que, impulsado por el calor y las privaciones, varias veces pidió por el amor de Dios que le dieran un poco de agua para beber. María, sensible a sus sufrimientos, gratiose porrigebat el agua que le había pedido. Trasladada a Sevilla con su ama, la esclava fue adquirida por Antonio da Bargagli, el esposo de Caterinetta.

Otro testigo, Benedetto di Dondedeo también embarcado en el navío de Napoleone Cigalla, después de ser liberado se trasladó a la isla de Fortis Venture (Fuerteventura) donde vio a María en la casa de la hija de Diegi de Errera de Sibilia, quien quería vendérsela, pero al no tener dinero el testigo rechazó la oferta. Su ama trataba a María como «servam chanariam ex insula Parme» (La Palma) y desde Fortis Venture la había trasladado a España y en el Portus Sancte Marie la había vendido al esposo da Caterinetta como esclava de las Islas Canarias.

El último testigo, Gregorio de Bozolo, escriba en el navío de Antonio Nigrone, declaró que mientras estuvo en Sevilla había visto a María viviendo en la casa de la señora de las Islas Canarias y que era tratada como una esclava y considerada por todos como una canaria.

El documento no explica por qué se recogieron estos tres testimonios. Tal vez porque Caterinetta, la ama de la esclava sin nombre, quería demostrar la legitimidad de sus derechos de propriedad. O tal vez porque la esclava se había dirigido al Magistrato dei Supremi Sindicatori de Génova para que fuera declarada su esclavización como injusta, como lo hizo en 1487 una María que quería volver a ser una mujer libre alegando su origen hispano y no mauro. 


\section{DOC. 1}

1: 1425, Génova - los carniceros Antonio Palavania y Jacopo Pipo otorgan un poder a Antonio de Antonio porque recupere el esclavo mauro Lanzaroto que se había escapado junto con otro esclavo circasiano (ASGe - Lorenzo Villa f. 3, a.79)

2: 1462 Florencia - los mercaderes Centurioni entregan en Sevilla una esclava canaria a un patrón vasco para que la venda en Florencia

(ASGe - Bartolomeo Canessa f. 1, a. 13)

3: 1463 Génova - Battista Doria vende a Giovanni Focoberto, mercader de Mallorca, por 25 ducados el esclavo Jacobino de 14 ańos de progenie maurorum canarie

(AsGe - Tommaso Duracino f.7, a.16)

4: 1465 octubre 3, Génova - se vende a un mercader catalán, por 20 ducados una esclava canaria de 8 años ${ }^{68}$

(ASGe - Tommaso Duracino, f.8, a.537)

5: 1465 octubre 11, Génova - Marco de Muste, nauta, vende a Giovanni Focoberto mercader de Mallorca, por 122 liras la esclava Caterina maura di canaria de 20 años (ASGe - Tommaso Duracino, f.8, a.564)

6: 1466 Génova - Damiano de Franchi asegura por 175 liras contra los riesgos del parto la esclava Cazina de progenie Canariorum de 26 años al quinto mes de embarazo (ASGe - Tommaso Duracino f.9, a.72)

7: 1468 Génova - Pietro de Petra vende a Gabriele Marco, mercader de Valencia, por 80 liras la esclava Caterina maura de Canaria de 20 años (ASGe - Tommaso Duracino f.11, a. 225)

8: 1471 Génova - Giovan Battista de Savignone alquila por 8 años a Giovanni Salvago el esclavo Janicho de 30 años

(ASGe - Pelegro Testa f. 2, sett. 3)

9: Génova 1475: Battista Giustiniano vende al sedero Battista Tonso la esclava canaria Lucia de 27 años por 150 liras

(ASGe - Lorenzo Costa f. 7, a. 27)

10: Génova 1481: tres testigos declaran que la esclava Maria chanaria et de progenie canariorum de propiedad de Caterina de Bargaglio es originaria de la isla de la Goimera (ASGe - Emanuele Granello f. 2, a.36)

11: Génova 1482: Stefano Cavallo vende al herrero Antonio Pasqua la esclava canaria Aranicha de 8 años por 32 ducados

(ASGe - Bernardo Tassorello f.1. a.7)

12: Génova 1485: Bertuchia Odorico vende a Marco Benci de Siena la esclava canaria Caterina de progenie canariarum de 28 años por 47 ducados

(ASGe - Gerolamo Loggia f. 3, serie 1, a. 138)

67 HeErs, J.: Genes au XV siecle, op. cit., p. 494.

68 HeErs, J.: op. cit., p. 35. 
13: Génova 1486: Marsilio da Capriata vende al sedero Bartolomeo Sacco la esclava canaria Lucia de 30 años por 150 liras

(ASGe - Gerolamo Loggia f. 3, serie I, a. 288)

14: Siena 1487, mayo 14: Matteo del qm Giovanni Salvi de Siena, banquero, vende por 55 ducados de oro a Raffaello de Signorio de Savona la esclava Caterina de progenie canariarum de 30 ańos, sanam et nitidam (la misma esclava del doc. $\mathrm{xxx}$ ) (ASSi - Carte Salvi)

15: Génova 1487, febrero: Battista Valle entrega a Antonio Pinu la esclava Maddalena de progenie maurorum canariorum de 16 años para que la transporte a Sicilia a su riesgo (risico, periculo et fortuna Dei, mari et gentium) y la venda o la cambie (ASGe - Nicolò Raggi f. 17 a. 16)

16: Génova 1487, agosto 2: Battista Valle otorga una procura a Marco Cabella para que recupere en Sicilia la esclava Maddalena de progenie maurorum canariarum de 18 ańos o, en alternativa, el precio de su venta (ver doc. vvv)

(ASGe - Nicolò Raggi f. 17, a. 579)

17: Génova 1488, junio 4: Raffaele Centurione vende a Giovanni Begazio la pequeña esclava Maria de progenie maurorum seu canariorum por 30 ducados

18: Génova 1488, abril 2: Primaflore Ragio emancipa a la esclava Caterina de progenie maurorum seu canariorum de 37 años a condicion que la sirva para toda su vida (ASGe - Nicolò Raggi f. 18, a. 256)

19: Siena 1489, septiembre 14: Girolamo de Iacopo Spinola de Génova vende en Siena a Giovanni de Bichi, quien compra por su padre magnificus miles Antonio, la servam seu ancillam Caterina de 14 años, hija de Hysa de Sala de partibus Cannarie, por 52 ducados largos de oro.

(ASSi - Legato Bichi-Borghesi)

20: Siena 1495, octubre 20: Antonio Bichi de Siena emancipa a la esclava Caterina in premium sue servitutis (ver doc. $\mathrm{xx}$ ) y la casa con Cola Gobite homo liber ex partibus indianis. Como acto de gratitud el matrimonio se compromete a servir Antonio Bichi por 15 años como fideles famuli et amorosi ac solliciti servitores. (ASSi - Legato Bichi-Borghesi)

21: Valencia 1496, febrero 12: El M.R. recibe de micer Nicolás Cathero, mercader veneciano, 42 sls. por las 31 lbs. en que ha vendido un cautivo blanco de Tenerife. (A.R.V., C.M.R., 21, fol. 51.) ${ }^{69}$

22: 1496 Génova, agosto 2: en su testamento Barnaba Carrega deja a su esposa la esclava canaria Caterina (sin indicación de la edad)

(ASGe - Biagio Foglietta f. 2)

23: 1496 Génova: Lazzaro de Canalis vende al lanero Geronimo de Bardis la esclava canaria Margherita de 22 años por 130 liras (ASGe - Lorenzo Costa, fl. 17, a. 98)

${ }^{69}$ Cortes, V.: op. cit., p. 536. 
24: 1496 Génova: el confector Simone Riccio vende al notaro una esclava canaria sin nombre de 11 años por 123 liras

(ASGe - Nicolò Raggi, fl. 23, a. 793)

25: Génova 1496: el sedero Gabriele de Otone vende la esclava canaria Anna de 14 años a Pietro de Mari por 200 liras

(ASGe - Antonio Pastorino, f. 11, a. 138)

26: Génova 1498, marzo 26: el magnificus dominus Francesco Cibo vende a Pietro de Mari la esclava Anna de progenie maurorum canarie de 14 años por 200 liras.

(ASGe - Nicoló Raggi, fl.26 n. 269)

27: Venecia 1498, noviembre 19: Antonius Bassus vende unum suum scravum Martinicum, de generatione Canaria, de 13 ańos por 25 ducados sine defectu caduci morbi vel aliis defectibus secundum morem patrie

(ASVe - Giovanni Bonetti, Cancelleria inferiore. Notai, busta 29)70.

70 Verlinden, C.: "Le recrutement des esclaves à Venise aux XIV e XV siecles», Bulletin de l'Institut historique belge de Rome 1968, vol. 39, p. 182. 


\section{DOC. 2}

Génova 1481: tres testigos declaran que la esclava Maria chanaria et de progenie canariorum de propiedad de Caterina de Bargaglio es originaria de la isla de la Goimera ASGe, Notai antichi, 872 , n. 36

Transcripción de Giustina Olgiati, Archivio Nazionale di Genova

1481, noviembre 22, Génova

Testimonianza di Gregorio di Bozolo fu Simone, cittadino di Génova.

1481, diciembre 5, Genova

Testimonianza di Benedetto de Dondedeo, cittadino di Genova.

Extractum]

1481 testificaciones XXI novembris

In nomine Domini, amen. Ex hoc publico instrumento cuntis pateat evidenter quod, constitutus in presencia reverendi domini locumtenentis et vicarii archiepiscopi ianuensis ac mei notarii et testium infrascriptorum, Thedixius Lercarius, filius domini Andree, testis summarie productus per Caterinetam, uxorem Antonii de Bargalio civis Ianue, probare volentem ad eternam rei memoriam ne fides veri pereat quod Maria, serva dicti Antonii, est chanaria et de progenie canariorum et pro canaria eam emit in Ispania et sic tractabatur et reputabatur ab omnibus cognoscentibus eam, admonitus et eidem delato iuramento per me notarium infrascriptum, de mandato prefati domini locumtenentis et vicarii, de veritate dicenda et veritati testimonium perhibendum et de eo quod sciverit et fuerit interrogatus super predictis, dicto titulo eidem prius lecto et per eum plene intellecto, suo iuramento testificando dixit se tantum scire de contentis in dicto titulo videlicet quod, dum alias, modo esse possunt anni quatuor in circa, ipse Tedixius esset in nave patronizata per Neapolionum Cigallam, que ob procellam maris ivit ad quendam insulam Canarie nominatam Gomeriam, ipse testis, dum descendisset in terram sub fide, fuit captus et captivus stetit per aliquos menses sub potestate domini Diegi Errerii chavalerii Sibiliensis, domini dicte insule et aliarum Chanarie, vidit multociens dictam Mariam que tunc stabat cum domina Maria, filia dicti domini Diegi, pro sclava et tanquam sclava inducta more chanarearum serviebat / in domo dicte domine Marie et eidem Marie serve, et dum ipse testis detinebatur in carceribus, pluries requisivit ut (1), amore Dei, vellet ei dare aliquantulum aque pro bibendo, de qua eidem testi gratiose porrigebat. Scitque etiam quod dicta domina Maria dictam Maria $<\mathrm{m}>$ conduxit tanquam servam ad aliquas insulas Canarie, ad quas causa eas vixitandi accedebat, et postremo missit eam in Ispaniam. Postea vero intellexit quod vendita fuit dicta Maria dicto Antonio, et hoc est quod scit de contentis in dicto titulo.

Interrogatus de causa scientie < respondit> per ea que supra dixit et fuit testificatus.

Interrogatus si attinet producenti respondit non.

Interrogatus si ad eum spectat commodum vel incommodum de predictis respondit non. Interrogatus super aliis interrogatoriis generalibus, recte respondit et dixit velle obtinere ius habentem.

De quibus omnibus prefatus dominus vicarius mandavit dictaque Caterineta rogavit per me notarium infrascriptum confici debere presens publicum instrumentum, in fidem et testimonium premissorum.

Actum Ianue, ad bancum iuris curie archiepiscopalis ianuensis, anno dominice nativitatis $\mathrm{MCCCC}^{\circ} \mathrm{LXXX}$ primo, indicione XIIII secundum Ianue cursum, die mercurii vigessimo 
primo novembris, in vesperis, presentibus nobili Alaono Imperiali et Simone Biono Bartholomei, civibus Ianue, testibus ad premissa vocatis specialiter et rogatis.

In nomine Domini, amen. Noverint universi et singuli presens publicum instrumentum inspecturi quod, constitutus in presencia prefati reverendi domini locumtenentis et vicarii archiepiscopalis ianuensis ac mei notarii et testium infrascriptorum, Gregorius de Bozolo civis Ianue q. Simonis, testis summarie productus per dictam Caterinetam, uxorem dicti Antonii, probare volentem ad etternam rei memoriam, ne fides veri pereat, contenta in suprascripto instrumento superius intitulata per dictam Caterinetam, admonitus et qui iuravit et cetera, interrogatus et examinatus et cetera, dicto titulo et cetera, suo iuramento testificando dixit se tantum scire de contentis in dicto titulo quod, modo esse possunt fere anni quatuor, dum ipse testis esset in loco Sibilie scriba navis Nicolai de Nigrono, patronizata tunc per Aranum Squarzaficum, vidit dictam Mariam tunc commorante $<\mathrm{m}>$ in domo cuiusdam domini insularum Chanarie pro sclava chanaria et tanquam sclava (2) ei serviebat et pro chanaria tractabatur et reputabatur ab omnibus cognoscentibus eam. Scitque etiam quod dictus Antonius eam emit a quodam factore domine Marie, filii dicti domini insularum Chanarie, pro chanaria, quam postea ipse testis conduxit in dicta navi (3) et exegit naulum ac soluta fuerunt comerchia Ianue pro dicta Maria pro chanaria et tanquam chanaria. / Interrogatus de causa scientie respondit per ea que supra dixit et fuit testificatus et quia ipse testis tunc erat scriba dicte navis.

Interrogatus si attinet producenti respondit non.

Interrogatus si ad eum spectat commodum vel incommodum de predictis respondit non. Super aliis generalibus recte respondit.

De quibus omnibus et cetera.

Actum in loco suprascripto, anno et indicione suprascriptis, die vero iovis XXII novembris, in vesperis, presentibus Simone Biono Bartholomei et Baptista Risoto q. Gabrielis, civibus Ianue, testibus ad premissa vocatis specialiter et rogatis.

In nomine Domini amen. Constitutus in presentia prefati domini locumtenentis et vicarii ac mei notarii et testium infrascriptorum, Benedictus de Dondedeo civis Ianue, testis productus per dictam Caterinetam, probare volentem ad eternam rei memoriam, ne fides veri pereat, contenta in suprascripto primo instrumento, admonitus, interrogatus et examinatus per me notarium infrascriptum super contentis in dicto instrumento, delato prius per me dictum notarium infrascriptum eidem testi iuramento, tactis per ipsum manibus scripturis, suo iuramento testificando dixit se tantum scire de predictis videlicet quod anno de MCCCCLXX octavo, dum ipse testis esset scriba navis Raffaelis Lomelini, tunc patronizate per Neapolionum Cigallam, que ob procelam / maris ivit ad insulam Gomerie, unam ex insulis Chanarie, in qua ipse testis stetit captivus per aliquos menses, et cum liberatus esset et venisset ad insulam Fortis venture, vidit dictam Mariam in domo domine Marie, uxoris cuiusdam nobilis portugalensis et filie magnifici domini Diegi de Errera de Sibilia, domini insularum Chanarie, et quam eidem testi vendere voluit, sed quia ipse testis non habebat peccuniam eam emere recusavit, et que domina Maria tenebat dictam Mariam tanquam servam chanariam ex insula Parme et ex ea insula Fortis venture missit dictam Mariam pro serva in Ispaniam super quadam caravella super qua etiam ipse testis venit in Ispaniam, et cum esset in loco Portus Sancte Marie vidit quod dictus Antonius de Bargalio ind[e] (4) ad aliquos dies eam emit a Iohanne Maiorcha, factore dicte domine Marie, et in dicto loco Portus Sancte Marie erat dicta Maria tractata et reputata pro serva chanaria.

Interrogatus de causa scientie respondit per ea que supra dixit et fuit testificatus. 
Interrogatus si attinet producenti respondit non.

Interrogatus si ad eum spectat commodum vel incommodum de predictis respondit non. Super aliis interrogatoriis generalibus recte respondit.

De quibus omnibus et cetera.

Actum Ianue, in curia archiepiscopali ianuense, anno dominice nativitatis MCCCCLXXX primo, indicione XIIII secundum Ianue cursum, die mercurii quinta decembris, in vesperis, / presentibus Bartholomeo de Florentia q. Blasii et Simone Biono Bartholomei, civibus Ianue, testibus ad premissa vocatis specialiter et rogatis.

1. Segue depennato: eadem 2. Segue, depennato: chanaria 3. navi: corretto su precedente nave 4. Guasto per filza. 


\section{DOC. 3}

Siena, 14 de mayo de 1487

Matteo del qm Giovanni Salvi de Siena, banquero, vende por 55 ducados de oro a Raffaello de Signorio de Savona la esclava Caterina de progenie canariarum de 30 ańos, (la misma esclava del doc. 14)

(ASSiena - Carte Salvi)

Texto integral en PrunaI, G.: «: «Notizie e documenti sulla servitù domestica nel territorio senese secc. VIII-XVI»

In nomine Domini, amen. Anno ab ipsius Domini salutifera incarnatione millesimo quadringentesimo octuagesimo septimo, indictione quinta, secundum stilum et consuetudinem notariorum civitatis Senarum, die vero. XIIII. mensis maii, tempore beatissimi in Cristo patris et domini, domini Innocentii, divina providentia, pape octavi, et regnante serenissimo principe et domino, domino Federico, romanorum imperatore semper augusto, ut Sen is comuniter fertur. Appareat omnibus evidenter quod egregius mercator Matheus olim Iohannis de Salvis, bancherius de Senis, dedit, vendidit et tradidit Raphaeli de Signorio de Savona, presenti, recipienti et ementi pro se et suis heredibus et successoribus unam ipsius (Mathei] sclavam, nomine Caterina, de progenie Canariarum, etatis annorum triginta vel circa, sanam et nitidarn, secundum consuetudinem civitatis Ianue, ad habendum, tenendum et gaudendum dicta sclava et quicquid deinceps dicto Raphaeli et suis heredibus et successoribus placuerit faciendum et disponendum, pro pretio et nomine pretii quinquaginta ducatorum auri in auro, quos dictus Matheus, venditor, fuit confessus et recognovit dicto Raphaeli emptori se ab eo habuisse et recepisse integre et numeratos et non sub spe alicuius future numerationis vel receptionis, exceptioni non numerate pecunie et non soluti dicti pretii ornnino renunptiante. Et promisit dictus Matheus, venditor, pro se et suos heredes et successores, dicto Raphaeli, emptori, recipienri et stipulanti ut supra, dictam sclavam venditam eidem legiptime defendere, autorizare et distrigare ab omni persona, loco, comuni, collegio et universitate.

Etc.

Siena, 14 de septiembre de 1489

Girolamo di Jacopo Spinola de Genova vende en Siena a Giovanni Bichi, que compra por su padre Antonio, la esclava Caterina, de partibus Canarie.

(ASSiena, Legato Bichi - Borghesi, n. 181)

Texto integral en Prunai G.: «: «Notizie e documenti sulla servitù domestica nel territorio senese secc. VIII-XVI»

In nomine domini nostri Iesu Cristi, amen. Anno ab ipsius salutifera incarnatione millesimo quatrincentesimo octuagesimo nono, indictione octava, secundum stilum, praticam, consuetudinem et comunem observantiam notariorum civitatis senensis, die vero decima quarta mensis septembris, tempore pontificatus beatissimi in Cristo patris et domini, domini Inocentii, divina providentia, pape octavi, regnanteque serenissimo principe et domino, domino Federico tertio, divina favente clementia romanorum imperatore semper augusto, ut comuniter Senis fertur. Pateat omnibus evidenter qualiter spectabilis vir dominus Hieronimus domini Jacobi Spinola de Ianua, per se suosque heredes et successores, iure dominii et plene proprietatis et possexionis et in perpetuum, dedit, vendidit et tradidit spectabili 
et generoso militi domino lohanni domini Antonii domini Iohannis de Bichis de Senis presenti, ementi et recipienti pro magnifico milite domino Antonio domini Iohannis de Bichis de Senis predicto eius patre et pro eius domini Antonii heredibus et successoribus, unam eius domini Hieronimi servam seu ancillam, nomine Caterinam, filiam Hyse, de Sala, de partibus Cannarie, etatis annorum quatuordecim vel circa, cum signo in mento coloris quasi viridis et cum una parva cruce in facie sub oculo dextero, ad habendum, tenendum et possidendum et quidquid dicto emptori, ut supra presenti, ementi et recipienti et ipsius domini Antonii heredibus et successoribus deinceps perpetuo placuerit faciendum, cum omnibus et singulis iuribus suis et cum omnibus et singulis que dicta res vendita habet et continet in et super se, in, super, intra, infra seu supra se, in integrum omnique iure et ratione, usu seu requisitione sibi ex ea et pro ea re vendita aut eius occasione modo aliquo pertinentibus et spectantibus et in antea competituris, pro pretio et nomine pretii quinquaginta duorum ducatorum auri largorum ad rectum pondus magnifici comunis senensis, quod quidem pretium fuit confessus et recognovit dicto emptori, ut supra presenti, ementi et recipienti, se ab eo habuisse et recepisse in ducatis et pecunia numeratis et non sub spe alicuius future numerationis vel receptionis;

Etc.

Siena, 20 de octubre de 1495

Antonio Bichi emancipa a la esclava Caterina y la casa con el homo liber Cola Gobite. Como acto de gratitud el matrimonio se compromete a servirlo por 15 años.

(ASSiena - Legato Bichi-Borghesi)

Texto integral en Prunai G.: «: «Notizie e documenti sulla servitù domestica nel territorio senese secc. VIII-XVI»

In nomine Domini nostri Iesu Cristi, amen. Anno ab ipsius incarnatione quadringentesimo nonagesimo quinto, indictione decima quarta, secundum stilum et consuetudinem notariorum et iudicum alme Universitatis Mercantie civitatis senensis, tempore pontificatus Alecsandri sexti, divina providentia, pontificis maximi, regnante serenissimo principe et domino, domino Maximiliano, romanorum rege, imperatore invi-ctissimo et semper augusto, die vero vigesima sexta octubris dicti anni. Cum hoc sit quod magnificus ac generosus eques dominus Antonius Bichus de Senis, in presentiarum generalis conmissarius reipublice senensis et nominatim in terra Montis Politiani, iam sex annis prossime decursis, vero et iusto titulo emptionis, emerit a domino Ieronimo Spinola, ianuense, quan-dam sclavam nomine Caterinam, pro pretio et nomine pretii ducatorum quin-quaginta duorum auri boni et iusti ponderis, ut asseruit, pro serviendo ei-dem, ad instar aliarum sclavarum et fidelium servitricium, ut moris est hodiernis temporibus ex antiqua et approbata consuetudine, more et stilu in partibus italicis et extra, et bene, legaliter et fideliter pro dicto tempore, eidem servierit, volens erga eam uti maxima sui animi liberalitate, in premium sue servitutis, mere, libere, ex proposito et deliberato animo, dedit et eidem concessit omnimodam libertatem, ponendo ipsam in pristinum statum iuris naturalis, quo omnes tam mares quam femine nascebantur liberi. Et etiam ultra predicta, titulo et causa donationis inter vivos, ita quod nulla ingra-titudinis causa vel offensa valeat revocari, idem dominus Antonius dedit et donavit eidem Caterine, presenti et recipienti et michi notario infrascripto, ut publice persone et publico offitio fungenti, stipulanti et ut supra recipienti vice et nomine ipsius Caterine et pro eadem, dictos quinquaginta duos ducatos, pro ea traditos et solutos supradicto domino Ieronimo venditori tempore emptionis predicte, et omne ius quod habet et in futurum habere posset tam in persona ipsius Caterine quam etiam in dicta denarii quantitate. Et ad hoc 
etiam, ut prefata Caterina recognoscat premia libertatis et statum sue primeve condictionis, ex nunc prefatus dominus Antonius ipsam in matrimonio collocavit et dedit in veram et legitimam uxorem et pro uxore, per verba de presenti et anuli inmissionem et subarrationem et per verum et legitimum consensum hinc inde intervenientem, Cole Gobite, ex partibus indianis, homini libero et in eius potestate constituto, presenti, recipienti et ipsam in veram et legitimam uxorem acceptanti illis modis et formis qui requiruntur in quolibet vero et legitimo instrumento et contractu matrimoniali et secundum ordinem et formam sacrorum canonum et sacrarum constitutionum sancte matris ecclesie. Et ex adverso prefati Colas maritus et Caterina uxor, volentes recognoscere bonam fidem versus prefatum dominum Antonium donatorem et acceptorum benefitiorum non esse ingratos, in reconpensationem munerum et benefitiorum predictorum, nullo errore iuris vel facti ducti nec fraude aliqua vel dolo intervenienti, sed eorum et cuiuslibet ipsorum mera, libera et spontanea volumptate et ex certa scientia, promiserunt et ex pacto sollempni stipu-latione vallato, convenerunt per aquilianam stipulationem precedentem et acceptillationem legitime subsequentem prefato domino Antonio et mihi notario infrascripto, stipulanti et recipienti pro se et suis heredibus et suis in futurum subcessoribus, ut supra, stare, comnorari et familiariter habitari et cuilibet servire suisque filiis et heredibus in licitis et honestis, bene, legaliter, fideliter et sine fraude, prout facere tenentur et obligati sunt boni et fideles famuli et amorosi ac solliciti servitores, per annos quindecim proxime futuros, incipiendo a die presentis contracti et ut sequitur finiendos, dando et donando omnes eorum operas et servitia, toto dicto tempore, prefato domino Antonio, ut supra scriptum, pro se et filiis suis et heredibus, sine aliquo pretio, premio vel mercede, omni iuris et facti penitus exceptione rerpota, cum hoc tamen pacto et condictione expressis et declaratis in principio, medio et fine presentis contractus quod prefatus dominus Antonius eiusque filii et heredes et in futurum successores teneantur et debeant et obligati sint prefatis Cole et Caterine dare et tradere condecentem et convenientem victum et vestitum pro dictis quindecim annis, secundum qualitatem earum personarum; Etc. 


\section{DOC. 4}

1488, 2 de abril - Génova

Primaflos quondam Antonio de Pendula y viuda de Giacomo Raggio dona la libertad a su esclava Caterina, de progenie Maurorum seu Canariorum, a condición que sigua sirviéndola hasta su muerte o a servir su nieta Gerolama, hija de su hermano Pellegro de Pendula, si muriera dentro de quince ańos.

(Archivio di Stato di Genova, Notai Antichi 1030, doc. 356)

Transcripción Valentina Ruzzin

+ In nomine Domini amen. Cum sit quod de iure naturali omnes homines oriantur liberi et servitus per ius gentium contra ius naturale fuerit introducta, et ad ipsius servitutis extinctione fuerit per dictum ius gentium manumissionis beneficium adinventum, ideoque Primaflos, filia quondam Antonii de Pendula et uxor quondam Iacobi Ragii, ob multa grata, servicia et beneficia per ipsam habita et recepta a Catalina, eius serva et sclava de progenie Maurorum seu Canariorum, etatis annorum triginta septem vel circa, etiam in remedium anime dicte Primefloris, volens eidem Cataline gratiam facere specialem, eandem Catalinam, licet absentem, per me notarium infrascriptum, officio publico, stipulantem et recipientem nomine et vice dicte Cataline a , salvis et sub condictionibus infrascriptis, liberavit, manumissit et franchivit et a manu et potestate ipsius Primefloris ac ab omni vinculo et iugo servitutis exemit et liberavit ac absolvit, eidem Cataline, licet absenti, salvis infrascriptis, largiens et concedens meram, puram ec floridam libertatem, ita quod dicta Catalina, salvis infrascriptis, sit libera, francha et sui iuris possitque testari, codicillari, emere, vendere, sibi acquirere, in iamdicto iure venire, et omnes contractus et iudiciarios a[c] tus $^{\mathrm{b}}$ facere et ${ }^{\mathrm{c}}$ celebrare ac si nata fuisset libera et in libertate et numquam fuisset dedita in dominium alicuius, et prout potest quelibet mulier Romana et exitens sui iuris, salvo tamen iure patronorum in ipsa Primaflore et eius heredibus, et salvis condictionibus infrascriptis, videlicet quod dicta Catalina teneatur et debeat ${ }^{\mathrm{d}}$ et cogi possit servire et famulari eidem Primeflori in vita ipsius Primefloris et quamdiu ipsa ${ }^{\mathrm{e}}$ viverit bene legaliter et dilengenter, et si ipsa Primaflos decederit infra annos quindecim proxime venturos quod ipsa Catalina teneatur et debeat ${ }^{\mathrm{f}}$ et cogi possit servire et famulari bene legaliter et diligenter Hyeronime filie quondam Pelegri de Pendula, fratris dicte Primefloris, annis quinque et per annos quinque sive tempore annorum quinque tantum. Renuncians dicta Primaflos exceptioni dicte franchisie, liberacionis et manumissionis ut supra et cum dictis condictionibus non facte, rei sic ut supra non esse vel non fuisse, sei sic non se habens vel aliter se habens, doli, mali, metus in factum, actioni, condicioni ${ }^{\mathrm{g}}$ sine causa vel ex iniusta causa et necnon beneficio / senatus consulti Veleyani, legi Iulie de fondo ${ }^{\text {h }}$ dotali, autentice «Si qua mulier» et omni alii iuri et legum ${ }^{\mathrm{i}}$ auxilio quibus contra predicta ${ }^{\mathrm{j}}$ et infrascripta venire posset vel aliqualiter protep $<s>$ tari, certiorata prius dicta Primaflos per me notarium infrascriptum de dictis iuribus et beneficiis quid sint et dicant. Quam quidem manumissionem, liberacionem et franchysiam et omnia et singula suprascripta promist dicta ${ }^{k}$ Primaflos et iuravit ad sancta Dei evangelia, corporaliter tactis scripturis, salvis tamen predictis, michi dicto infrascripto notario, ut supra stipulanti et recipienti et per me eidem Cataline, licet absenti, firmam, ratam et gratam et firma, rata et grata habere et tenere, actendere, complere et observare, contraque in aliquo modo non facere, ducere vel venire per se ${ }^{1}$ vel alium aliqua ratione, occasione vel causa, cogitata vel non, et que modo aliquo vel ingenio, de iure vel de facto, dici vel excogitari possit ${ }^{* * *}$, sub pena dupli tocius eius et quo seu de quo contrafactum foret, vel ut supra non observatum, solemni stipulatione promissa ${ }^{* * *}$, et cum restitutione 
damnorum omnium, interesse et expensarum que propterea fierent seu essent, litis et extra, ratis manentibus suprascriptis, et sub ypoteca et obligatione bonorum omnium ipsius Primefloris, presentium et futurorum. Faciens dicta Primaflos predicta omnia et singula in presencia, cum et de consilio Hyeronimi Capelli quondam Iohannis, et Tome de Canicia, filii ${ }^{\mathrm{m}}$ Bartholomei, propinquorum suorum ex melioribus, ut dixit, iurantium ad sancta Dei evangelia, corporaliter tactis scripturis, sese credere predicta omnia et singula fieri potius ${ }^{n}$ ad comodum et utilitatem dicte Primefloris quam ad aliquod eius damnum vel lesionem. Actum Ianue, in Fossatello, ad bancum mei notarii infrascripti, anno dominice nativitatis $\mathrm{M}^{\circ} \mathrm{CCCCLXXXVIII}{ }^{\circ}$, indictione quinta iuxta morem Ianue, die mercurii secunda aprillis, in vesperis. Testes Pelegrus de Octonello, speciarius, quondam Antonii ${ }^{\circ}$ et Iohannes de Marasio, bambaxarius, quondam Bartholomei, vocati et rogati.

${ }^{\mathrm{a}}$ nomine - Cataline nell'interlineo ${ }^{\mathrm{b}}$ foro della filza ${ }^{\mathrm{c}}$ facere et nell' interlineo ${ }^{\mathrm{d}}$ segue depennato et ad hoc ${ }^{\mathrm{e}}$ ipsa nell'interlineo ${ }^{\mathrm{f}}$ segue depennato servire ${ }^{\mathrm{g}}$ condicioni corretto ${ }^{\mathrm{h}}$ fondo cosi ${ }^{\mathrm{i}}$ segue depennato ax au ${ }^{\mathrm{j}}$ segue depennato ve $\mathrm{re}^{\mathrm{k}}$ segue depennato $\mathrm{Pf}^{1}$ segue depennato $\mathrm{se}^{\mathrm{m}}$ filii corretto ${ }^{n}$ potius nell'interlineo ${ }^{\circ}$ segue depennato et Baptista. 


\section{DOC. 5}

1466, 3 de marzo - Génova

El ciudadano genovés Leonardo di Negro quondam Angelo subscribe un seguro de 275 liras contra los riesgos del parto de Cazina, esclava de diecisiete ańos de progenie Canariorum, al quinto mes de embarazo.

(Archivio di Stato di Genova, Notai Antichi 896, doc. 72)

Transcripción Valentina Ruzzin

Asecuratio sclave ${ }^{\text {a }}$.

In nomine Domini amen. Leonardus de Nigro, civis Ianue, quondam Angeli, sponte et ex certa scientia confessus fuit et confitetur et in veritate publice recognovit et recognoscit mihi notario infrascripto, tanquam publice persone officio publico stipulanti et recipienti nomine et vice Damiani de Franchis de Burgaro, et per per me, dictum notarium infrascriptum, eidem Damiano, licet absenti, se a dicto Damiano seu ab alia persona pro eo emisse, habuisse et recepisse tantam quantitatem suorum rerum ${ }^{b}$ et mercium bonorum mercantilium causa infrascripta ${ }^{* * *}$, renuncians et cetera ${ }^{* * *}$, unde et pro qua quantitate dictarum rerum et mercium, seu precio et valoris ipsarum, dictus Leonardus per se et heredes suos se obligavit, promisit et solemniter convenit ${ }^{c}$ mihi dicto notario infrascripto, ut supra stipulanti et recipienti nomine et vice dicti Damiani, licet absentis ut supra, eidem Damiano vel persone pro eo legitime dare et solvere seu dari et solveri facere realiter et cum effectu quod hinc ad menses sex proxime venturos libras centum septuaginta quinque ianuinorum monete currentis ${ }^{* * *}$, sub pena dupli ${ }^{* * *} /$ ratis et cetera ${ }^{* * *}$, et proinde et cetera ***. Salvo et specialiter reservato <quod $>$ si quidam sclava ipsius dicti Damiani, nominata Cazina, de progenie Canariorum, etatis annorum decem septem vel circa, gravida seu pregnans mensium quinque vel circa, de partu suo et de dicte eius gravidacione, pregnatione et partu, et occasione ipsius gravidacione, pregnatione et partu viva evaserit, quod tunc et eo casu presens instrumentum sit cassum, irritum et nullum ${ }^{* * * d}$. Actum Ianue, in Bancis, sub porticu domus Angeli de Nigro et fratris, videlicet ad bancum residencie mei notarii infrascripti, anno dominice nativitatis $\mathrm{M}^{\circ} \mathrm{CCCCLXVI}$, indictione XIII ${ }^{a}$ secundum Ianue cursus, die lune tercia marcii, hora signi meridiei, presentibus testibus Raynaldo Iustiniano quondam Argoni et Bartholomeo de Roncaiolo quondam Iohannis, civibus Ianue ad hec vocatis et rogatis.

${ }^{a}$ Asecuratio sclave nel margine superiore, al centro del foglio ${ }^{\mathrm{b}}$ suorum rerum corretto ${ }^{\mathrm{c}}$ segue depennato dicto ${ }^{\mathrm{d}}$ segue, non espunto sit enim cassum. 